NBSIR 82-2554

\title{
Health and Safety Considerations for Passive Solar Heated and Cooled Buildings
}

U.S. DEPARTMENT OF COMMERCE National Bureau of Standards National Engineering Laboratory Washington, DC 20234

August 1982

Prepared for

U.S. Department of Energy

Dancive and Hybrid Solar Energy Division

- $\mathrm{C}$ - e of Solar Heat Technologies

100 sington, DC 20585

.456

$32-2554$

1932 

HEALTH AND SAFETY CONSIDERATIONS FOR PASSIVE SOLAR HEATED AND COOLED BUILDINGS

F. Eugene Metz James H. Pielert Patrick W. Cooke

Center for Building Technology

and

William D. W/alton

Center for Fire Research

U.S. DEPARTMENT OF COMMERCE

National Bureau of Standards

National Engineering Laboratory

Washington, DC 20234

Augus! 1982

Prepared for

U.S. Department of Energy

Passive and Hybrid Solar Energy Division

Office of Solar Heat Technologies

Washington, DC 20585

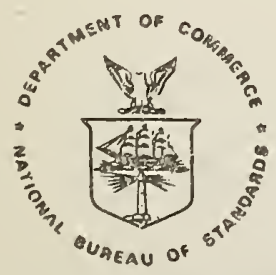

U.S. DEPARTMEINT OF COMMERCE, Malcolm Baldrige, Secretary NATIONAL BUREAU of STANDARDS. Emest Ambler, Director 


\section{ABSTRACT}

This report discusses the nature of health and safety considerations in applying solar passive technology to buildings and how they would be affected by current building regulatory requirements. Health and safety considerations associated with solar passive systems are discussed including: indoor air quality; structural safety; fire safety; and environmental issues such as ventilation, 1llumination, temperature control, humidity and nolse control. The report also identifies technical issues and research needs associated with health and safety concerns in passive solar technology.

Keywords: Bulldings; building regulations; energy; enforcement; health and safety; passive design; solar energy; standards. 
This research was conducted by the Building Economics and Regulatory Technology Division of the Center for Building Technology, National Engineering Laboratory, National Bureau of Standards (NBS). The work was sponsored by the U.S. Department of Energy as part of its effort to provide for the technical acceptance of passive solar energy applications in buildings.

The use of solar energy by passive solar design and construction techniques is generally perceived to be quite positive and certainly not a threat to health and safety. There are, however, techniques that are being used and explored that are potentially hazardous. This document attempts to identify and discuss some of these problem areas.

Investigation of existing building codes and standards indicates that their enforcement could restrict the application of some common passive techniques. This study includes an analysis of the model building codes and related regulatory documents to determine the content of regulations which could adversely impact widespread dissemination of the technology. This information is related to health and safety issues which have been associated with passive systems including fire safety, indoor air quality, physical hazards, and structural safety. Special appreciation is extended to $\mathrm{Mr}$. Robert Dikkers, Research Coordinator, NBS Solar Technology Program, for guidance and encouragement throughout this effort. Appreciation is also extended to Ms. Belinda Reeder whose thorough technical review and suggestions were most valuable. The assistance of the CBT Word Processing Center in the typing of this report is gratefully acknowledged. 


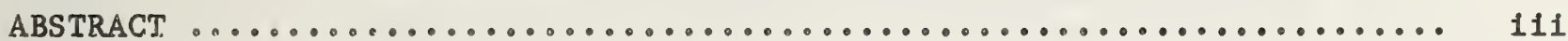

PREFACE $\ldots \ldots \ldots \ldots \ldots \ldots \ldots \ldots \ldots \ldots \ldots \ldots \ldots \ldots \ldots \ldots \ldots \ldots \ldots \ldots \ldots \ldots \ldots \ldots$ Iv

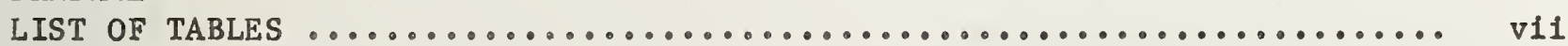

1. INTRODUCTION ......................................

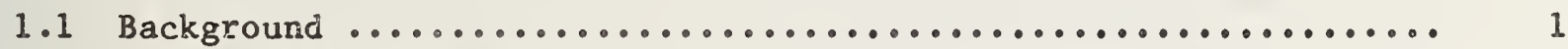

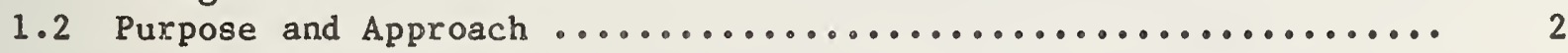

2. CHARACTERISTICS OF PASSIVE SOLAR BUILDINGS .................. 4

2.1 Passive Solar Heating systems ...................... 4

2.2 Passive Solar Cooling systems ......................... 8

3. BUILDING REGULATIONS ................................ 10

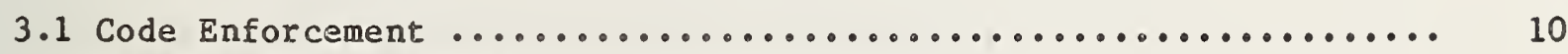

3.2 Passive Solar Retrofit ............................. 11

4. HEALTH AND SAFETY CONSIDERATIONS ......................... 13

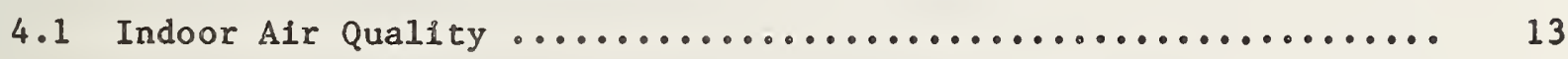

4.1.1 Pollutant Sources in Passive Solar Buildings .......... 13

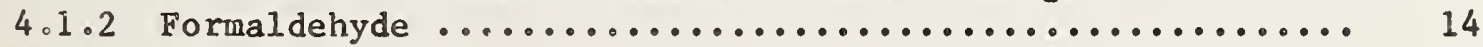

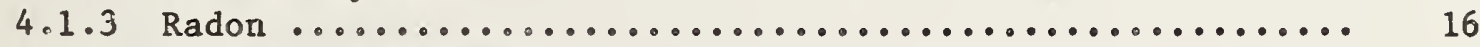

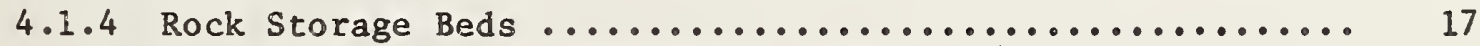

4.1.5 Building Regulations Related to Indoor Air Quality ..... 17

4.2 Basic Environmental Requirements .................... 18

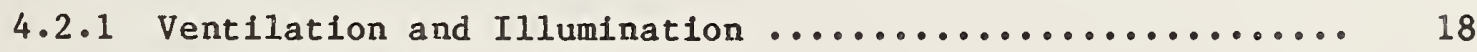

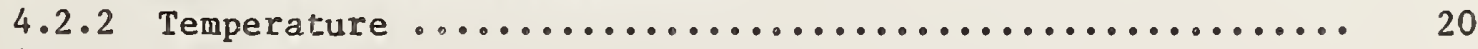

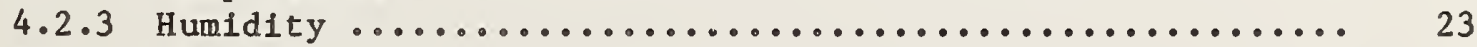

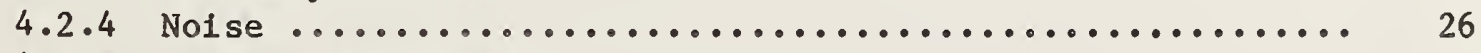

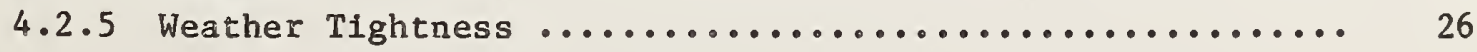

4.3 Fire Safety $\ldots \ldots \ldots \ldots \ldots \ldots \ldots \ldots \ldots \ldots \ldots \ldots \ldots \ldots \ldots \ldots \ldots \ldots \ldots$

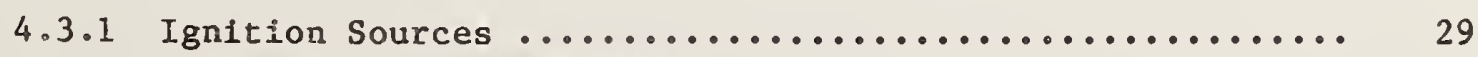

4.3 .2 Ignitability of Materials ...................... 31

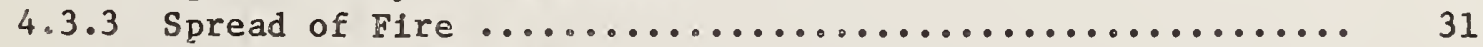

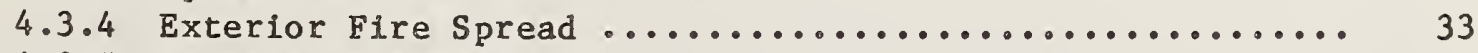

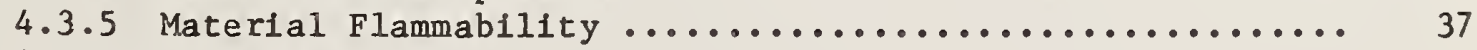

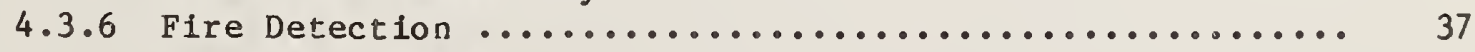

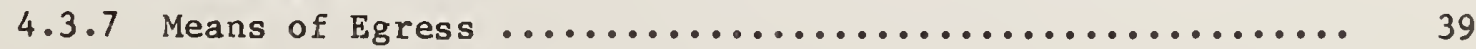


4.3.8 Generation and Spread of Products of Combustion ....... 39

4.3 .9 Emergency Access .......................... 41

4.4 Structural Considerations $\ldots \ldots \ldots \ldots \ldots \ldots \ldots \ldots \ldots \ldots \ldots \ldots \ldots \ldots \ldots$

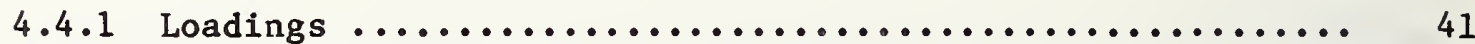

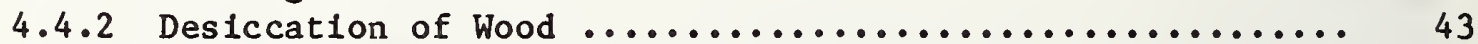

4.4 .3 Glazing Considerations ...................... 45

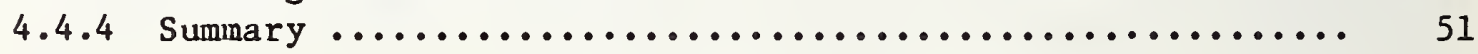

5. SUMMARY AND RECOMMENDATIONS $\ldots \ldots \ldots \ldots \ldots \ldots \ldots \ldots \ldots \ldots \ldots \ldots \ldots \ldots \ldots \ldots . \ldots \ldots$

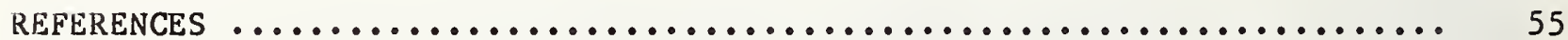


Table 4.1 Ventilation Criteria $\ldots \ldots \ldots \ldots \ldots \ldots \ldots \ldots \ldots \ldots \ldots \ldots$

Table 4.2 Illumination Criteria ......................... 21

Table 4.3 Criteria for Protection Against Decay and Termites ........ 24

Table 4.4 Criteria for Venting of Attic spaces ................ 25

Table 4.5 Criteria for Sound Transmission Control .............. 27

Table 4.6 Fire Safety (Clearances from Heated Surfaces) .......... 30

Table 4.7 Fire Safety (Vertical Shafts, Fire Dampers, Plenums, and Atriums) $\ldots \ldots \ldots \ldots \ldots \ldots \ldots \ldots \ldots \ldots \ldots . \ldots \ldots . \ldots \ldots$

Table 4.8 Fire Safety (Fire stopping) ..................... 34

Table 4.9 Fire Safety (Material Flammability) ................ 38

Table 4.10 Fire Safety (Means of Egress) .................... 40

Táble 4.11 Structural Design Criteria in Codes ................. 42

Table 4.12 Glazing Design Criteria in Codes .................. 46 


\section{INTRODUCTION}

\subsection{BACKGROUND}

Passive solar systems make use of the site, form and materials of the bullding to collect (or dissipate), store, and distribute solar energy to its occupants. Energy transfers to and from the building and within the building rely primarily on natural processes, $1 . e$, conduction, convection, and radiation with minimal dependence on external power and mechanical equipment such as fans and pumps. Many building components can serve dual functions; $1 . e .$, enclosure and structural stability as well as "capturing" and distributing energy. Passive heating, cooling, and daylighting, therefore, are intrinsic to the building, and are affected by its siting, orientation, spatial configuration, circulation, window and door placement, use of building materials and other characteristics. There is considerable information confirming the adequacy of the technology, cost effectiveness, and thermal comfort provided by passive solar buildings. This information is resulting in the popularity and growth of passive solar applications. Such technologies have and will continue to lead to the development of unique building details and material applications. However, these applications may introduce new safety and health considerations within the building environment which are generally not encountered in conventional construction.

Investigation of existing building codes and standards indicates that their strict enforcement could substantially restrict the application of some common passive techniques. Although there has been little regulatory resistance to passive buildings to date, future applications on a larger scale with various occupancy types will likely face nore stringent code enforcement. If regulatory code restraint.s become a problem, it may be necessary to develop alternative regulations or design solutions in order to ensure that healthy and safe conditions prevail.

The increased use of passive solar applications includes two somewhat opposite trends that have significant implications for health and safety of building occupants. First, as design techniques and the reliability of passive systems are improving, there is increasing application of these techniques in larger non-residential buildings. This has two implications: (a) in the event of a safety problem, the results could be more extensive and affect more people, and (b) there is increasing likelihood of regulatory constraints since regulations for such buildings tend to be more restrictive. Like the development of all building technologies, the successful and safe application of passive solar techniques relies primarily upon sound building design with particular attention to construction detail. Competent building design professionals should be involved in applying the technologies, so the likelihood of any hazard is reduced.

A second trend, resulting from growing popularity, available guidelines and apparent simplicity of passive solar design is the increased involvement of the "do-it-yourselfer." In this case, lack of sufficient knowledge may lead to potential hazards. There are also problems regarding building code enforcement 
in such instances since the "do-it-yourselfer" may often circumvent the building regulatory system by doing work outside the building permit process. According to Balcomb, "the apparent simplicity of passive solar building has misled many people into thinking that passive solar design is simple. In fact it is a complex process, a subtle complexity consisting of consciously designing to take advantage of environmental energies and natural processes" [1]. 1/

The use of solar energy is generally considered environmentally harmless, presenting few health concerns. However, applications of technical innovations could introduce new construction practices which may result in conditions that are potentially harmful to the health, safety, and welfare of the occupants. Accordingly, it is important to identify such practices in the initial stages of their development in order to more consciously control their application through the design process. An excellent source of technical information for naterials used in solar systems and with an emphasis on environmental and safety considerations has been completed by Sandia National Laboratories [2]

\subsection{PURPOSE AND APPROACH}

This research was conducted to identify and understand the nature of health and safety considerations in passive solar buildings. These considerations are related to current building regulations applied to such buildings. It is necessary that health and safety issues be considered to allow for the technology to continue rapid development.

The study focuses on two aspects of the impact of building regulations: (1) how they may act as constraints to the effective utilization of the technology; and (2) how they may not adequately address the new and unusual health and safety considerations associated with the technology. Generally, current building codes cover passive solar construction practices which do not vary greatly from conventional building construction practices. However, the prescriptive nature of some code requirements often restrict the use of passive solar technologies which depend upon slight variations to typical construction practice. Moreover, there is the issue of passive solar applications which result in radical variations from standard construction techniques. Not specifically covered by existing regulations, these departures depend most critically upon sound design and construction to ensure safety. This study addresses these issues and identifies areas in which additional research is needed to support definitive safety criteria.

The purpose of this report is to present an overview of the current state of passive solar technology; summarize relevant health and safety issues; discuss the status and impact of regulatory coverage in the model building codes and other related documents; and to identify and discuss technical issues and research needs for promoting broader acceptance of the technology. Building code constraints affecting passive solar which are not health and safety related are not discussed in this report.

1/ References are listed on page 55. 
The health and safety topics included are fire safety, indoor air quality, physical hazards, environmental requirements (ecg., illumination, temperature control, humidity, noise), and structural safety. The nature of this investgation is general and is intended to relate to most building occupancy types except those classified as industrial. Residential, small scale commercial and Institutional buildings will be emphasized because most of the passive solar activity to date has been in this area and this trend is expected to continue.

The possibilities for redesigning existing buildings to incorporate passive solar technologies are widespread and have thus far proven to be very successfut. The current economic climate has tended to reinforce this kind of solar application. Therefore, regulatory issues of particular concern to the retrofitting of existing buildings are also covered.

3 


\section{CHARACTERISTICS OF PASSIVE SOLAR BUILDINGS}

There are five essential components of passive solar systems: Collectors collect the available energy from the sun. Virtually any material on the exterior of a building becomes a potential collector when exposed to direct or indirect solar radiation. Glass windows are among the most effective collectors since they admit a large portion of the sun's energy but prevent it from escaping after it is converted to heat or thermal energy by striking dark objects. Absorbers are dark colored surfaces or objects such as floors or walls which convert the sun's short wave radiant energy into longer wave thermal energy. Dense materials such as stone, concrete, masonry, and water are used as absorbers in buildings. Storage is any mass such as masonry floors, walls, or containers of water which retain the thermal energy collected from the sun until it can be used (usually when direct solar energy is not available). Distribution is the means by which thermal energy is moved from the point of collection or storage to occupied spaces. This is most frequently accomplished by the natural means of convection, radiation, and conduction using such building elements as walls, openings, and spaces. Ducts, plenums, pipes, and vents are also often used. The selective use of fans and blowers is sometimes required. The term hybrid is frequently used to describe systems in which devices using depletable energy (usually electricity) are used to distribute solar energy, but this report wili consider those as passive. Controls are important to prevent excessive overheating and underheating. Shading devices such as properly sized roof overhangs, operable vents, movable insulation, and reflectors are examples of control techniques. Controls are also intrinsically linked to system design, sizing, relative locations of collection and storage areas, energy load requirements, and scheduling of energy use.

\subsection{PASSIVE SOLAR HEATING SYSTEMS}

Passive heating systems are solar systems in which the building structure is designed to collect the sun's energy, store the energy, and distribute the resulting heat by natural means. Specific systems which utilize these concepts are discussed below.

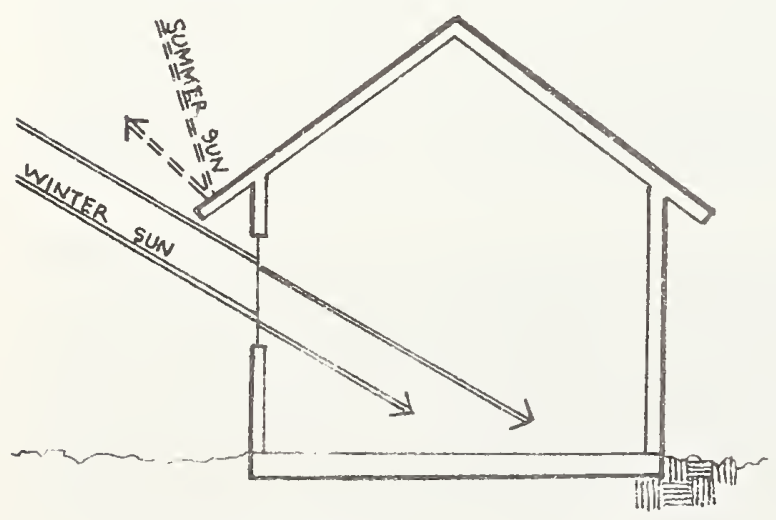

Sun-Tempered Buildings can be considered as conventional with special attention given to oxientation and south-facing windows.

Sun-Tempered 


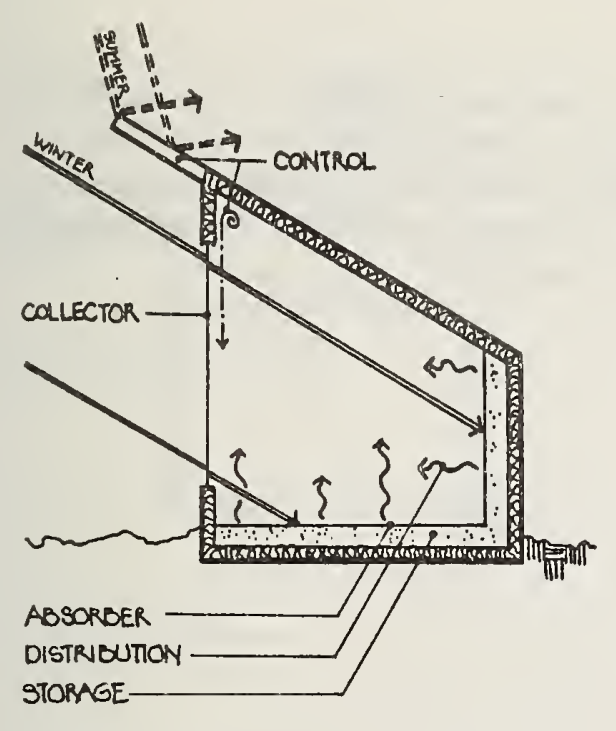

Direct Gain
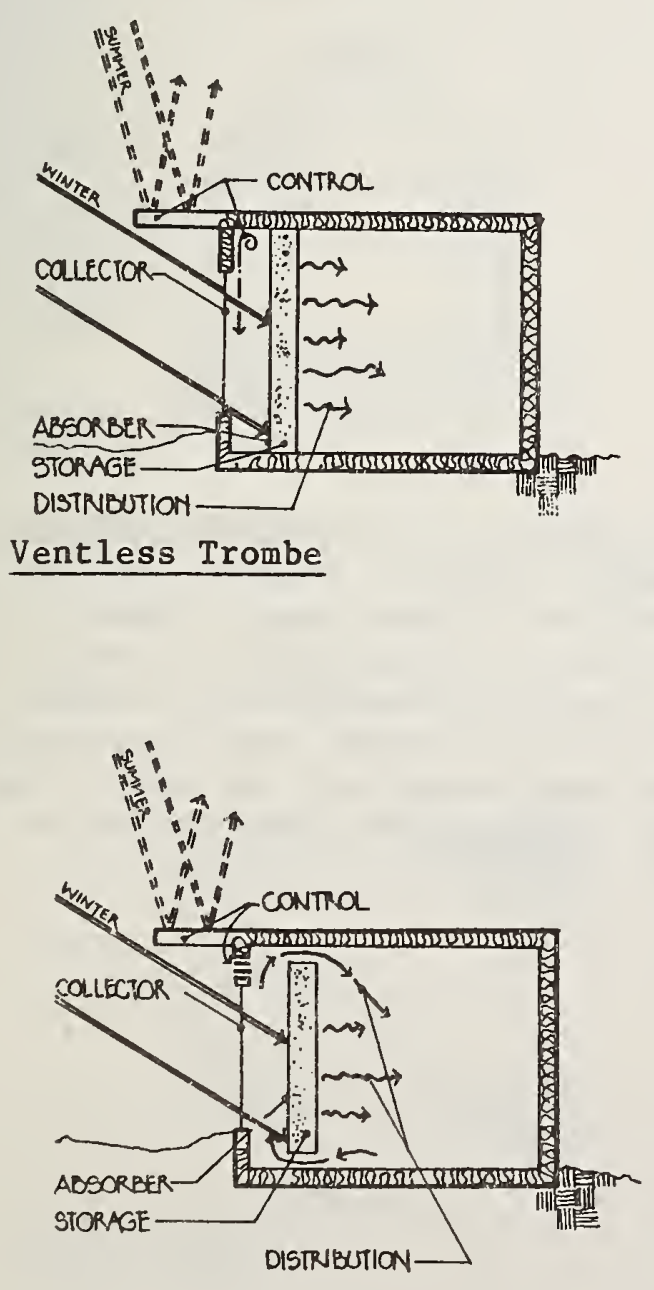

Vented Trombe

\section{- GENERIC PASSIVE TYPES}

Direct Gain is the most common and simplest passive solar concept and usually differs from sun tempering by the provision for substantial storage mass as part of the interior living spaces adjacent to increased southfacing windows or other glazed openings.

\begin{abstract}
Storage Wall (indirect gain ... Trombe wall) is a passive technique in which storage mass is positioned immediately behind south-facing glazing and separates the glazed solar energy collection area from occupied spaces. Although this is an unusual building feature, it is normally constructed of conventional building materials and methods.
\end{abstract}




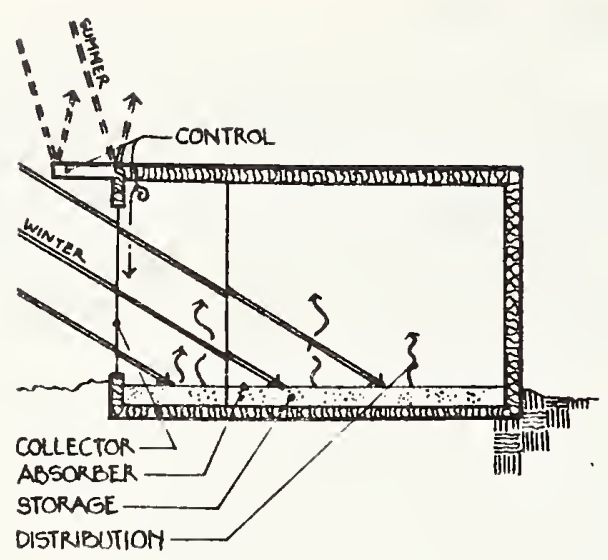

Sunspace With Direct Gain Wall

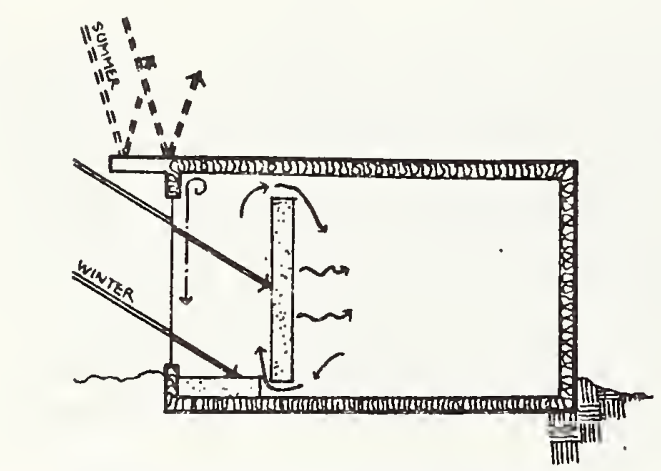

Sunspace With Storage Wall

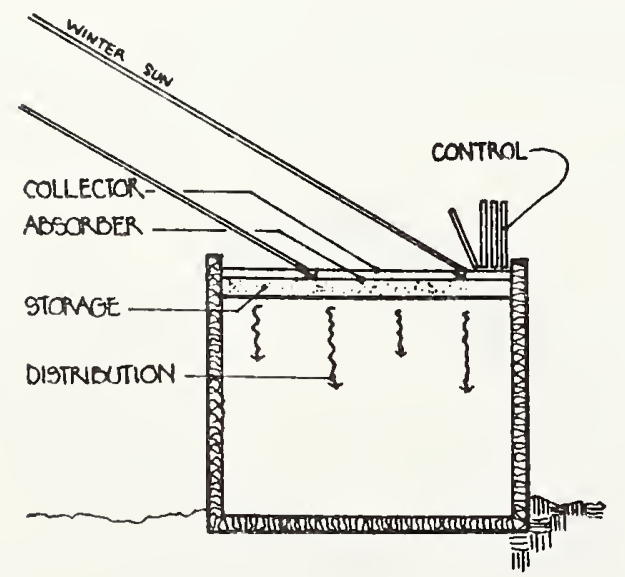

Storage Roof
Sunspace (isolated gain ... greenhouse, solarium) collects and stores solar energy in a secondary space separate from but thermally linked to adjacent occupied spaces.
The Storage Roof (roof pond) concept is considered a special case of Indirect Gain with very large bags of water on the building roof providing storage mass. The roof construction, supporting structural system, and heavy-duty movable insulation over the water bags are the most unusual characteristics of this system. 


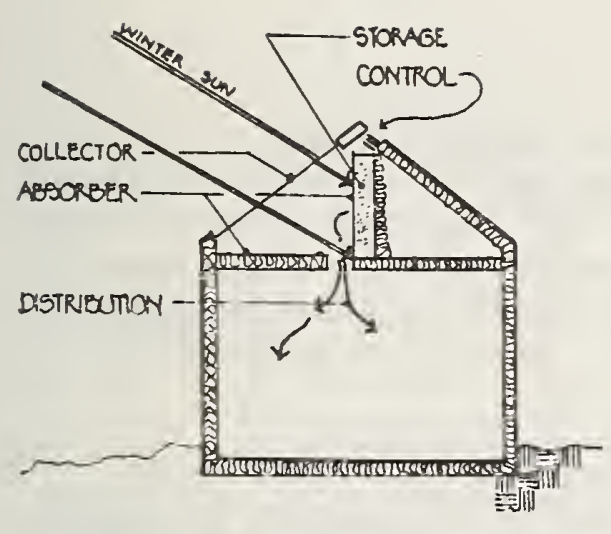

Solar Attic

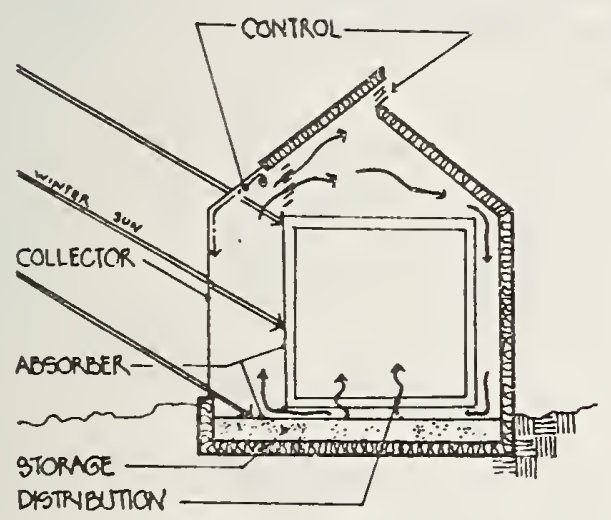

Double Envelope

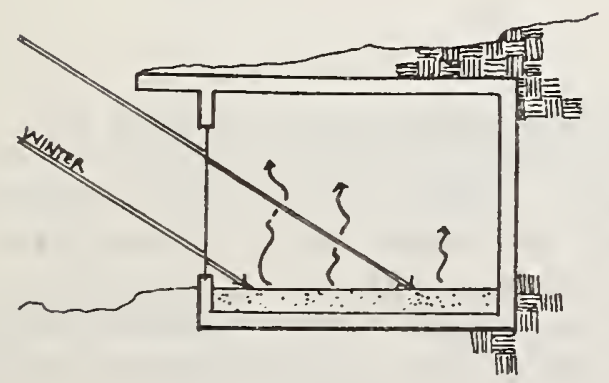

Earth Contact

\section{SPECIAL TYPES}

Solar Attics may be considered a special case of Sunspace. The southfacing portion of the roof is glazed and acts as a collector. The attic floor (and perhaps walls) are dark colored and act as absorbers. Storage may or may not be provided on the attic floor or adjacent walls.

The Double Envelope is unique although the solar energy coliection is usually similar to the Isolated Gain or Sunspace type. The concept of circulating a stream of solar warmed air through double wall and attic spaces requires unusual construction methods for structural framing and sheathing.

Earth Contact Buildings vary from below ground structures to those having earth berms covering major portions of one or more exterior walls of a building. These buildings may have other passive features but they are distinguished primarily by the fact that they are at least partially below finished grade. 


\subsection{PASSIVE SOLAR COOLING SYSTEMS}

Passively cooled buildings are designed to minimize summer daytime heat gain and to utilize nighttime coolness and the cool night sky for heat loss. Properly placed windows provide for the circulation of cool air removing the heat which has accumulated in the storage materials during the day. Overhanging eaves to shade windows, insulated windows and shutters, and selective location of shade trees all contrihute to keeping the building cool. Specific systems which utilize these concepts are discussed below.

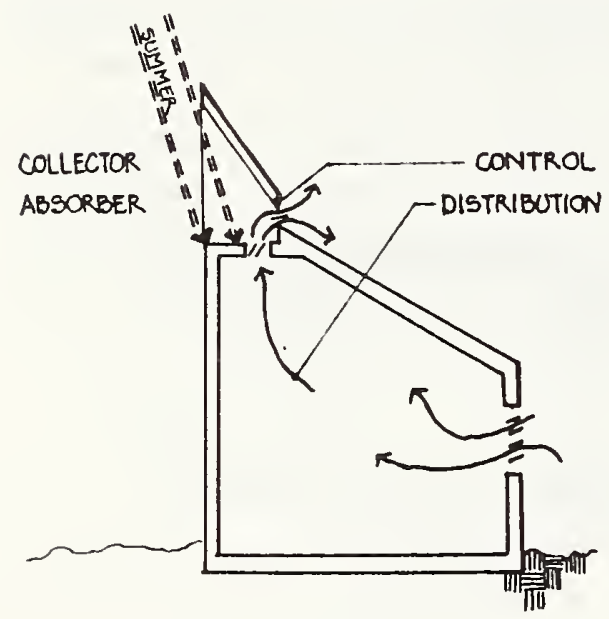

Induced Ventilation

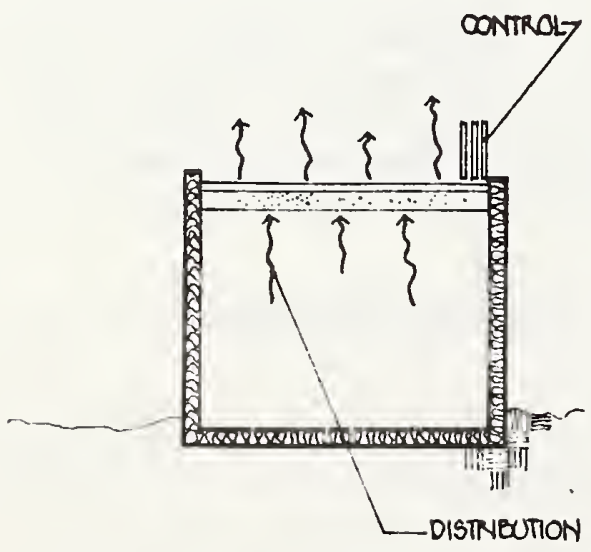

Night Sky Radiation
Induced Ventilation. A "thermal chimney" effect is created by solar heating in a restricter area, which facilitates the rise and external venting of hot air. Replacement air is drawn from adjacent occupied spaces which in turn is replaced by air taken from cooler outdoor sources.

Night Sky Radiation. Cooling is achieved by exposing a massive body of water, masonry, or possibly metal to the cool night sky. During the day, the mass acts as "cold storage" that can absorb heat from the interior occupied spaces. The storage roof and storage wall techniques discussed earlier are common approaches to night sky radiation. Solar attics may also be alapted for this purpose. 


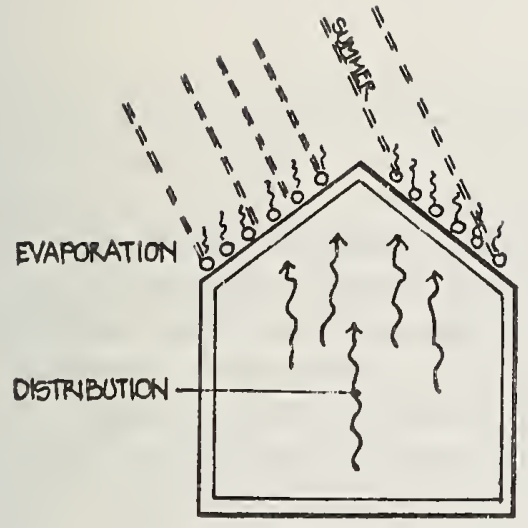

\section{Evaporative Cooling}

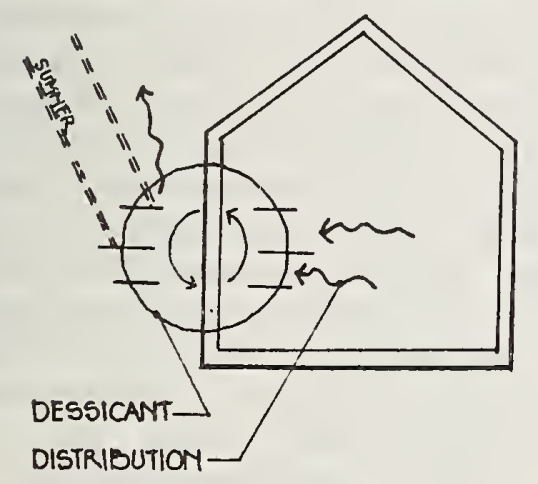

\section{Dessicant Cooling}

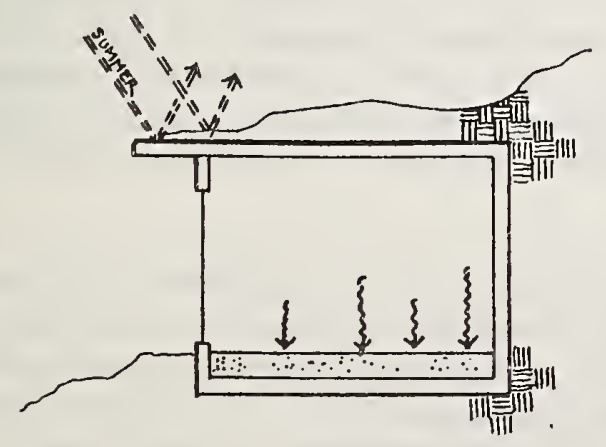

Evaporative Cooling. A source of water or a body of water is required which can be evaporated to decrease the sensible temperature.
Dessicant Cooling. This technique increases cooling comfort by the drying of very humid air which enhances the natural cooling effect of sweat evaporation. The use of dessicant salts (which can be dried by solar), induced ventilation (as described earlier as the thermal chimney effect), or some dehumidifiers will provide dessicant cooling.
Earth Contact. Building below grade to take advantage of cool and relatively stable earth temperatures, as discussed earlier, is one form of cooling by earth contact. "Cool tubes" which extend underground well beyond the building periphery and use the relatively low earth temperature to cool fresh air, is another type.

\section{$\underline{\text { Earth Contact }}$}

This is not intended to be a thorough analysis of passive solar techniques. It is to be noted that there can be infinite variations of materials and methods used in applying existing passive solar technology. For a more complete analysis including typical sample projects, see references $[3,4]$. 


\section{BUILDINGS REGULATIONS}

\subsection{CODE ENFORCEMENT}

Building codes exist in most of the incorporated jurisdictions in the U.S. and exert control over how buildings are designed, built, and constructed. The purpose of building codes is to set forth rules to ensure that the building design protects the health, safety, and welfare of its occupants. Model building codes $[5,6,7,8]$ are in widespread use as the basis for most legal codes. Individual jurisdictions often adopt one of the models as their legal code; but frequently the models are amended, so diversity still exists.

Many states have enacted statewide building code programs in recent years, but unless the state code is totally preemptive and mandatory, most legal codes are the laws of cities and towns, and each one has the potential to be, and of ten is unique [9]. Local jurisdictions may also adopt special standards and criteria as guidelines such as those related to fire safety, energy conservation, or even solar energy applications. This cumbersome diversity of codes, tends to impede innovation and efficiency and is further compounded by variations in interpretations and enforcement by local officials. While progress has been made in developing uniformity between codes and code provisions and their enforcement, the multiplicity of codes, lack of codes, lack of uniformity, the enforcement procedures, their specificity as regards acceptable materials and methods of construction, and the ponderous amendment procedures, all work to restrict innovation. Unlike most regulatory processes which define prohibited practices, the building code defines acceptable practices, hence it restricts options [10]. Most of the technical provisions included within codes come directly or indirectly from hundreds of national standards that deal with engineering practices, material specifications, and test methods.

It is reasonable to expect that the incorporation of passive solar systems into buildings should not create a built environment which is more hazardous or unhealthful to the occupants than that of a conventional building. Requiring minimum health and safety standards are clearly the major concerns of building codes. However, strict interpretation and enforcement of the existing language of many present building codes and standards with regard to health and safety issues could substantially restrict the application of certain passive solar technologies.

There have been few reported incidents of restrictive code enforcement applied to passive solar construction. The more frequent response is one of confusion and an indication that building officials do not understand passive solar systems and that guidelines are needed. An attempt has been made to provide such guidelines and this has resulted in, "Recommended Requirements to Code Dfficials for Solar Heating, Cooling and Hot Water Systems" [11]. This document was developed for the Departinent of Energy by the Council of American Building officials ( $C A B O$ ) and provides an excellent commentary on some of the more significant safety problems of passive solar construction. The document primarily addresses active solar energy systems with the assumption that current building codes adequately cover the concerns of passive solar techniques. However, passive technology continues to develop, adding new concerns to those that have not been fully resolved. 
It has been reported that bullding of ficials tend to be lenient with regard to questionable passive techniques and exercise a willingness to "go along in the interest of energy conservation." Such leniency cannot always be anticipated from one jurisdiction to another. For building permit purposes, one code official suggested that perhaps buildings should not be promoted as "passive." This supports the idea that the regulation of passive solar construction should be no more and no less vigorous than for conventional construction.

As will be discussed later, some characteristics of passive solar systems may exceed regulatory minimums while some techniques could present potentlal hazards. This situation provides opportunities and justification for applying alternate solutions based on equivalent performance. Each of the model building codes provides for the building official to approve alternate materials and methods and to exercise judgment where some features are not specifically covered. These provisions also mandate that the building official shall require sufficient evidence to justify alternative methods. Although this provides a means for the approval of alternative techniques, it places the burden of proof on the designer which could be considerable. The building official who is unfamiliar with passive solar is also at a disadvantage and may be reluctant to make judgments without a firm technical basis. He would prefer to have prescriptive standards to follow. For these reasons, it is necessary to develop sound regulatory requirements and supportfing technical guidelines which allow continued development of the technology through system design innovation, but also provide a sound base from which subsequent: evaluation for code compliance can occur.

\subsection{PASSIVE SOLAR RETROFIT}

The nature of current regulations as applied to existing buildings can have a significant impact on the solar retrofit [12]. In general, builaing codes address the following categorfes of bullding rehabilitation: (I) additions to existing buildings; (2) maintenance, alteration, and repair of buildings not involving a change of use or occupancy; and (3) maintenance, alteration, and repair of bulldings involving a change of use or occupancy. Rehabilitation Guidelines [13] published by the Department of Housing and Urban Development provides detailed analysis of code coverage for existing buildings.

The model building codes generally require that the entire building comply with the new construction. requirements for the new occupancy when a change-in-use is involved. When no change of occupancy is involved, most building codes contain provisions, variously worded, requiring that a bufiding's conformance with the requirements of a currently enforced building code for new construction should increase in relation to the dollar amount of the rehabilitation planned. This mechanism for triggering compliance with new construction codes is known as the "25-50 percent rule" and is contained in the following sections of the model building codes: Basic Building Code [5] - Section 106.0 (1978 Edition); National Building Code [6] -- Section 104.3 (1976 Edition); Standard Building Code [7] - Section 101.4 (1979 Edition); and Uniform Building Code [8] Section 104 (1976 Edition). 
The application of these administrative provisions is based on the following general economic hierarchy:

1. The entire building must comply with the building code for new construction when alterations exceed 50 percent of the building's value,

2. The extent of conformance of the building altered to new construction requirements is up to the discretion of the bullding official when the cost is between 25-50 percent of the bullding's value, or

3. The alteration must be restored to at least its original condition for an alteration which costs less than 25 percent of the value of the building.

There are serious economic implications in applying these buiding code provisions when solar retrofitting an existing bullding. Costs of modifications could trigger the "25-50 percent rule" and require compliance with the code for new construction. For example, if the cost of the solar retrofit exceeded 50 percent of the value of the bullding (assuming use and occupancy remain unchanged), then other building systems must be upgraded even though they would be unaffected by the retrofit. This may cause the planned retrofit to be unfeasible from an economic viewpoint.

Recognizing this potential constraint to the broad acceptance of solar energy applications in buildings, the previously referenced document [11] addresses this issue in the following section:

\section{"G-101.5 Existing Buildings}

Solar energy systems may be installed in, on, or adjacent to existing buildings or appurtenant structures without having the entire building or structure comply as required for new construction, provided the added solar energy systems and the affected portions of the existing building, mechanical, plumbing, and electrical systems comply with the applicable provisions of these recommended requirements." 


\section{HEALTH AND SAFETY CONSIDERATIONS}

Passive solar buildings may, in general, be as safe or safer than their conventional non-solar counterparts while having equal or greater comfort characteristics. There have been few reported incidents of health or safety related problems in passive solar buildings. The few known problems have been relatively minor or have been alleviated before actual harm occurred. Much of the discussion which follows relates to applications of building materials and systems and how they are affected by unique environmental conditions found in solar passive bulldings. This discussion is related to current building regulations which control the design of such buildings.

\subsection{INDOOR AIR QUALITY}

The probabilities of a buildup of indoor air pollutants due to characteristics of passive solar buildings have not been precisely determined, and the level of hazard they present is uncertain. There is, however, a large and growing concern for this potential health problem. A Department of Energy study [14] concluded that "the major environmental research problem associated with passive solar heating and cooling is indoor air quality." This concern results primarily from the energy conserving trend of greatly reducing air infiltration in buildings. This is an important conservation practice, one shared by passive techniques, because air infiltration may account for 50 percent or more of the heat load of a building. When this practice is combined with certain materials and techniques used in passively collecting, storing, and distributing solar energy, concerns may arise.

Reduced air infiltration results in higher concentrations of various pollutants emanating from interior sources and, therefore, a potential health problem. A recent article in the Journal of the American Medical Association (AMA) states, "The combination of hazardous materials in a tight structure simply allows these materials to build up rather than dilute" [15]. As reported in the April 1981 American Society of Heating, Refrigerating, and Air Conditioning Engineers (ASHRAE) Journal [16], the National Commission on Air Quality in issuing the final report of a three-year study of the Clean Air Act, addressing indoor air pollution for the first time. The same article cites a preliminary finding of a DoE study of houses in Oregon indicating that control of the pollution sources within a house may be preferable to eliminating the pollution through ventilation. Passive solar not only promotes this "tight" building concept but also may inadvertently increase the sources and incidence of indoor pollution.

\subsubsection{Pollutant Sources in Passive Solar Buildings}

Some of the pollutants and sources that are of concern especially in passive solar construction include:

- Formaldehyde and other toxic outgassing products - plywood, particle board and foam insulation (also furniture and carpeting). 
- Radon - mass storage components, masonry floors and walls, rock beds, earth storage (envelope construction), earth contact (underground and bermed earth).

Bacteria, fungus growth, dust - rock beds or other remote storage inedia, earth storage (heating and cooling systems), cool tubes.

Pesticides and other chemical treatments - solar greenhouses, crawlspaces, earth storage (double envelope construction), earth tubes.

In addition to the above sources, there are other interior environmental conditions prevalent in passive buildings that further aggravate the indoor air quality problem.

- Elevated temperatures at the point of collection/absorption of solar energy. This increases the emission of formaldehyde from plywood, particle board, urea-formaldehyde foams and furnishings including some carpets [17]. This effect is significant at moderate temperature levels, $27^{\circ} \mathrm{C}\left(80^{\circ} \mathrm{F}\right)$ to $32^{\circ} \mathrm{C}\left(90^{\circ} \mathrm{F}\right)$. Much higher temperatures, $93^{\circ} \mathrm{C}\left(200^{\circ} \mathrm{F}\right.$ ) to $150^{\circ} \mathrm{C}\left(300^{\circ} \mathrm{F}\right.$ ) (which may occur during stagnation) can result in outgassing of other materials including other types of insulation.

- Increased humidity also increases the emission of volatiles, especially formaldehyde [17]. High humidity also increases the potential for condensation and, therefore, mold, mildew, and fungus growth.

- Passage of the air stream through the structure of buildings (wall chases, attic, and crawlspaces), through the ground, and storage bins exposes building occupants to more pollutants, especially particulates.

- Reduced-air infiltration has been identified as elevating the concentration of indoor pollution, through this alone does not usually cause much of a problem unless sources of pollution are large.

- Miscellaneous contributors to the problem of indoor air quality may not be unique to passive solar but should be mentioned. The use of wood burning stoves, which are frequently used as backup sources of heat, may add a significant amount of pollution to the indoor air. Another concern that has been recently expressed is for the synergistic effect of pollutants combining either in or outside of the body to produce even more toxic substances. This would involve cleaning fluids and a whole host of chemicals and products that are now common in most buildings.

\subsubsection{Forinaldehyde}

Forinaldehyde is one of the most prominent of the indoor air contaminants. It is most cominonly associated with urea-formaldehyde foam insulation which has been the subject of a major regulatory controversy. This material has been tanned in some states including Massachusetts and the U.S. Consumer Product 
Safety Commission has taken action to ban the material completely effective June 1982. Other major sources include: (1) particleboard, used for underlayment, cabinets, furniture and paneling; (2) plywood paneling, especially hardwood plywoodl; (3) a variety of carpet types; and (4) resin-treated upholstery. Significant levels of indoor formaldehyde may also result from tobacco smoking and from poorly vented gas appliances.

The major source of formaldehyde in building materials is urea-formaldehyde resin which is used as an adhesive in wood products, and as a finishing agent in textiles. Fornaldehyde is released from the gas trapped in the product and from the hydrolytic decomposition of the resin polymer. Formaldehyde emissions decrease as the volatilizable gas is released and the product ages. Continued low-level long-term formaldehyde emissions will continue, however, as the ureaformaldehyde polymer undergoes hydrolytic decomposition. Because of this, as stated by researchers at Ball State University [18] . "...formaldehyde exposures and building-related illness may continue for years." The health effects include: eye and skin irritation, upper respiratory problems, headaches, dizziness, nausea, and fainting. Based on animal experiments, it is suspected of causing nasal passage cancer. Of great concern is the suspicion that formaldehyde may lead to the development of asthma, or to complications of asthmatic conditions. The dose-response relationship for the occupationally exposed adult has been identified [19].

Much of the data pertaining to formaldehyde release and occupant 11lness comes from investigations of mobile homes. One such study of 334 mobile homes reported formaldehyde concentrations ranging from $1.77 \mathrm{ppm}$ to a $10 \mathrm{w}$ of $0.03 \mathrm{ppm}$. A number of conventional houses and buildings, including offices and schools, have also had concentration levels resulting in illnesses. Many studies suggest a combination of "tightness" or low air infiltration and a substantial amount of formaldehyde releasing material is necessary before problems occur. Unless strong sources of formaldehyde are present in a home, energy-conserving measures aimed at "tightening up" houses should not lead to problems of indoor air quality due to formaldehyde [20].

Passive solar buildings which experience periodic elevation in temperature and humidity may increase the emission of formaldehyde from affected materials. An elevation of relative humidity from 30-60 percent at a given temperature will result in roughly a doubling of formaldehyde emissions [17]. Conditions in direct gain systems could lead to significantly elevated temperatures in carpets, upholstery and paneling. Particleboard, plywood and other materials used for the surfaces of solar attics or air collectors may reach temperature levels which would increase formaldehyde emission from these materials, causing them to be circulated into the air stream. Because of their potential for elevated humidity, attached solar greenhouses and earth contact buildings, including the use of the earth or crawl spaces as a heat sink, may produce problems, if materials containing formaldehyde are present.

1/ It should be noted that phenol-formaldehyde resin, primarily used in exterior grade plywoods, is much more stable that urea-formaldehyde, therefore resulting in only a fraction of the emission of formaldehyde. 
Radon is a substance known to be carcinogenic to humans at elevated levels. At lower levels its carcinogenic effect is unknown but strongly suspected. It is found primarily in the soil and ground water but it is also present in some masonry building materials. Fortunately, the presence of radon and its progeny at significantly high levels, is site specific. Its concentration in rocks and soils varies with location and, likewise, building products produced in various locations vary in radon concentration. Radon itself is inert and, therefore, not a primary health hazard. However, its presence and concentration is an indicator of the exposure to the biologically important radon decay products. Radon decays into four decay products which are alpha enitters. These decay products become airborne attaching themselves to particulates. If inhaled, they can enter the respiratory system and become lodged there. The primary health hazard is due to alpha particle emission of polonium-218 and -214. Alpha particles have a very short range and essentially all of the energy affects are near the surface of the lung. Continued exposure allows concentrated alpha particle emission in a relatively small area, causing serious effects.

Building materials which contain radon are granite, concrete blocks, earth masonry units, bricks, tile, and gypsum boards [21]. The variation of radon contents in similar materials may be very large. Other sources include soil, ground water, and natural gas. The indoor exposure levels from these sources can be significantly higher than outdoor levels [22]. This is dependent on location and building ventilation rates. The resulting health impact is enhanced risk of lung and other cancers [23].

The Swedish National Institute for Radiation Safety estimates that $1 \mathrm{pCi} / \mathrm{L}$ limit of radon corresponds to a cancer risk of 20-200 cases per million [24]. The maximum permissible concentration (MPC) for airborne radon concentrations recommended by the Health Physics Division of Oak Ridge National Laboratory should not exceed $3 \mathrm{pCi} / \mathrm{L}$. Some radon concentrations inside of buildings in the U.S. and various foreign countries are reported in the literature and they greatly exceed these recommended permissible levels [23]. Dr. Tom Hess of the University of Maine reports radon measurements levels of up to $200 \mathrm{pCi} / \mathrm{L}$ in some houses in the state. These houses were built in an area with outcroppings of granite and contained solar energy storage beds of crushed gravel.

The importance of the rate of ventilation and air tightness of buildings on radon concentration is demonstrated by recent investigations at the National Bureau of Standards (NBS) [25] . Relatively high concentrations of 8 to $18 \mathrm{pCi} / \mathrm{L}$ were measured in preliminary investigations of six thermal mass test buildings tested in the spring of the year. Tests conducted in the same buildings later in the fall showed that the air infiltration rate doubled along with the radon emanation rates. Measurements were similar in all six buildings although they vary in construction and materials from wood frame with wood siding to solid masonry walls. All six buildings have slabs on grade. Radon concentrations seem to be fairly well correlated with the air tightness of the buildings and not the type of construction. The buildings are extremely well sealed with the highest air leakage rate measured at $0.09 \mathrm{ACH}$ (air changes per hour). The buildings were rarely opened except for test purposes. 


\subsubsection{Rock Storage Beds}

Rock beds are commonly used for thermal energy storage in both active and passive solar systems. More typical for passive or hybrid systems, the rock beds are within the foundations and in contact with the floor slab above. This tends to make them inaccessable for monitoring or correcting any problems that might occur within them. There have been few reports of serious health problems associated with rock bed storage. There have been some problems with dust and odors. Warm rock beds have evaporated the water seal in the trap of drains of rock boxes permitting sewer gases to enter the air stream. In other cases, odors are suspected of being caused by mildew or fungus growth in the rock bed. Mildew is harmful to many materials but any specific health effects are not readily determined. It is, however, a strong indicator of the potential presence of other fungus and bacteria which may have health concerns.

Washing the rocks prior to installation can help eliminate dust and other impurities. Equal care in specifying the source of the rock will aid in avoiding hazardous materials such as those containing asbestos particles or radon gas. The unique hazard potential is created when passing the ventilating air stream through an uncertain and inaccessable medium.

\subsubsection{Building Regulations Related to Indoor Air Quality}

The model building codes address indoor air quality only in very general terms. Ventilation, however, is addressed in very specific terms and frequently in the the form of prescriptive requirements. The intent, as stated in the Minimum Property Standards of the U.S. Department of Housing and Urban Development [26]. "is to provide light and venilation to achieve a healthful environment within the dwelling and so located as to provide an acceptable degree of comfort." Illumination and ventilation requirements are discussed in section 4.2 .1 of this report including a tabular presentation of pertinent code provisions in the model building codes and related documents.

Designers and code officials alike have not fully anticipated the health problems that might be created by "tight" energy conserving buildings. Some codes require mechanical ventilation ... "when rooms, which by use or occupancy, involve the presence of dust, fumes, gases, vapors or other noxious or deleterious impurities that create a fire or health hazard" ... The provision further requires that, "ventilating systems shall be kept in operation at all times during normal occupancy of the building or space so used." This provision was likely written without the anticipation that building materials and furnishings might produce noxfous or deleterious impurities under some conditions. The NFPA Life Safety Code [27] does point out that features such as exposed insulation may establish a significant "Hazard of Content Level." This provision might have direct implications for many movable insulation techniques in passive solar, although there is no evidence of such an interpretation and enforcement of these provisions.

The CABO document [11] addresses solar applications even more directly by requiring filters at the outlet of rock storage beds when air is forced through the rocks and into habitable spaces. This requirement may significantly 
restrain those hybrid techniques which operate at a very low pressure drop as well as for systems which reverse air flow from rock beds for heating (or coo1ing) from storage. Required ventilation rates or requirements for operable windows, discussed inore fully in section 4.2.1, will also restrain some passive strategies.

ASHRAE Standard 62-81 [28] provides for a safe, healthful, and comfortable indoor environment by using materials and methods which optimize efficiency of energy utilization. It specifies acceptable levels of certain contaminants in the air within buildings and sets the minimum rates of ventilation necessary for human confort. Such contaminants may be present in makeup air or be introduced from indoor activities, furnishings, building materials, surface coatings, and air handing and air treatment components.

\subsection{BASIC ENVIRONMENTAL REQUIREMENTS}

This section discusses the issues of ventilation, illumination, temperature, humidity, and noise as related to passive solar design. It also includes a discussion of general considerations of health and sanitation sometimes referred to as environmental requirements -- room sizes and proportions, odor, rodents and vermin are examples. The health and safety effects of some of these issues are subtle; however, there is a broad agreement for most of the building regulations covering them.

\subsubsection{Ventilation and Illumination}

Ventilation is one of the most significant environmental and energy conservation issues. Table 4.1 summarizes ventilation requirements in the model building codes. Air movement as a means of achieving cooling is a common passive technique. The primary health concern is that the source of ventilating air be of acceptable quality, as was discussed in section 4.1, Indoor Air Quality. A second concern is for those cases where ventilation is greatly reduced in the interest of energy conservation with a detrimental effect on the quality of indoor air. A passive technique that is becoming increasingly popular is the collection of solar energy and the distribution of warm air through common building spaces such as atriums, corridors, stairways, etc. Most codes prohibit the circulation of supply/return air through multiple occupancies because of concerns for the spread of fire and smoke and potential sanitation problems. Some recent code changes contain specific requirements for atriums for fire and smoke protection (discussed under section 4.3, Fire Safety).

Minimum requirements for natural light and ventilation in building regulations are presented as a percentage of floor area. It is not clear how this ratio relates to specific health issues. This constant ratio could limit passive systens which tend to optimize the use of natural light, and ventilation. Also, wany passive solar designs for residential buildings call for minimizing exterior glazing on the east, west, and north exposures of buildings. Such designs directly conflict with the current code provisions requiring minimum glazing areas for natural light and minimum openable areas for natural ventilation in habitable rooms. These code provisions could inhibit the use of solar 


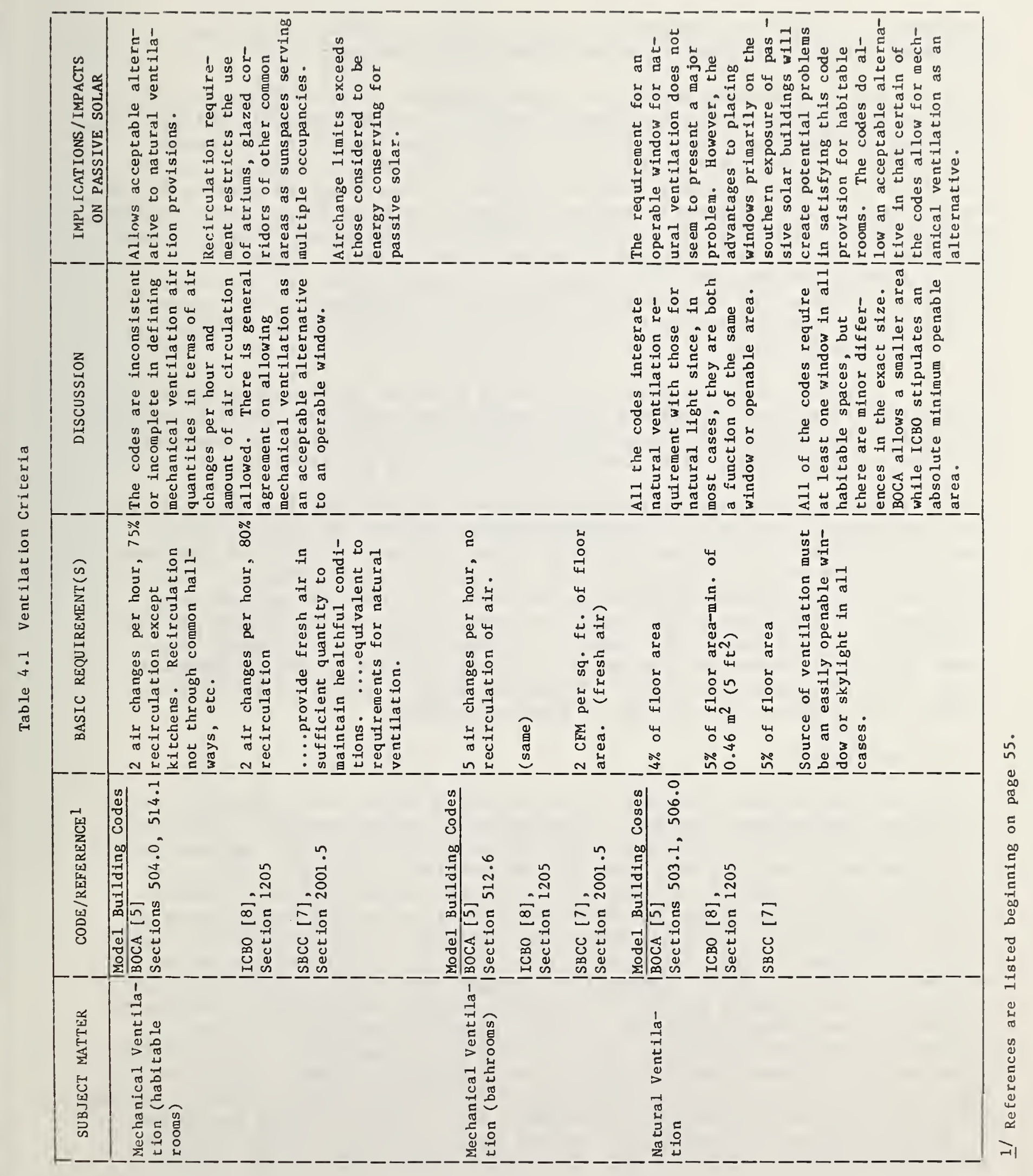


greenhouses in both new construction and retrofit situations if windows providing natural ventilation are no longer facing outdoors.

Illumination of habitable spaces is an environmental requirement of most building regulations. Natural light is generally required of all habitable and occupiable spaces as shown in table 4.2 although the safety and health implications are not clear. The use of windows for emergency egress and/or ventilation are given primary consideration. For some types of passive buildings, natural light is greatly reduced or even eliminated for northfacing rooms to decrease the heat loss attributed to windows. Underground or earth contact buildings sometimes have difficulty meeting these standards except for southfacing rooms where windows are concentrated. However, many earth contact buildings resolve this concern very adequately by orienting a large majority of habitable rooms to the south, providing atriums, light wells, skylights, and clearstory lighting.

The use of natural light to reduce the energy used for artificial lighting is a very important facet of passive solar systems when applied to many commercial buildings. Lighting often accounts for more than 50 percent of a commercial building's energy load, and it also increases cooling requirements.

Glare is another problem with health and safety implications that can result from the improper design of daylighting systems (as well as passive space heating techniques). The combination of large windows, reflector enhancement, and hard, dense surface areas can create substantial glare problems. Glare most often results from a bright light source with a contrasting low level of illunination. Glare can cause temporary impairment of vision and eye related discomfort. It was one of few "minor" problems reported in follow-up interviews in a recent survey of purchasers of passive houses in the residential solar demonstration program [29]. Proper and careful design of daylighting systems can eliminate the problem of glare altogether.

\subsubsection{Temperature}

Significant temperature fluctuations can result from improperly designed and controlled passive solar systems. Overheating or rapid heat loss from habitable spaces can occur if there is a poorly designed relationship between aperture, storage or building mass, venting and shading devices or other control techniques. For example, if there is an improper balance between collector area and surface area of the storage mass, excessive surface temperatures can result. Specifically, this can occur when relatively dark, high density materials, that might be used for flooring, are directly irradiated by the sun for substantial time periods. If resulting ambient and radiant temperature fluctuations are not properly matched to occupant comfort requirements (relative to age, health, and schedule/type of activity), health problems could result. Moderate temperature variations can be tolerated or compensated for by healthy, young adults. Infants, the elderly and the infirm may be more susceptible to these conditions with respect to discomfort and possibly health effects, although there is little medical evidence to support this. Health effects may become of greater concern relative to the various age, health, and activity groups as temperature fluctuations increase. The rate of temperature change and the 


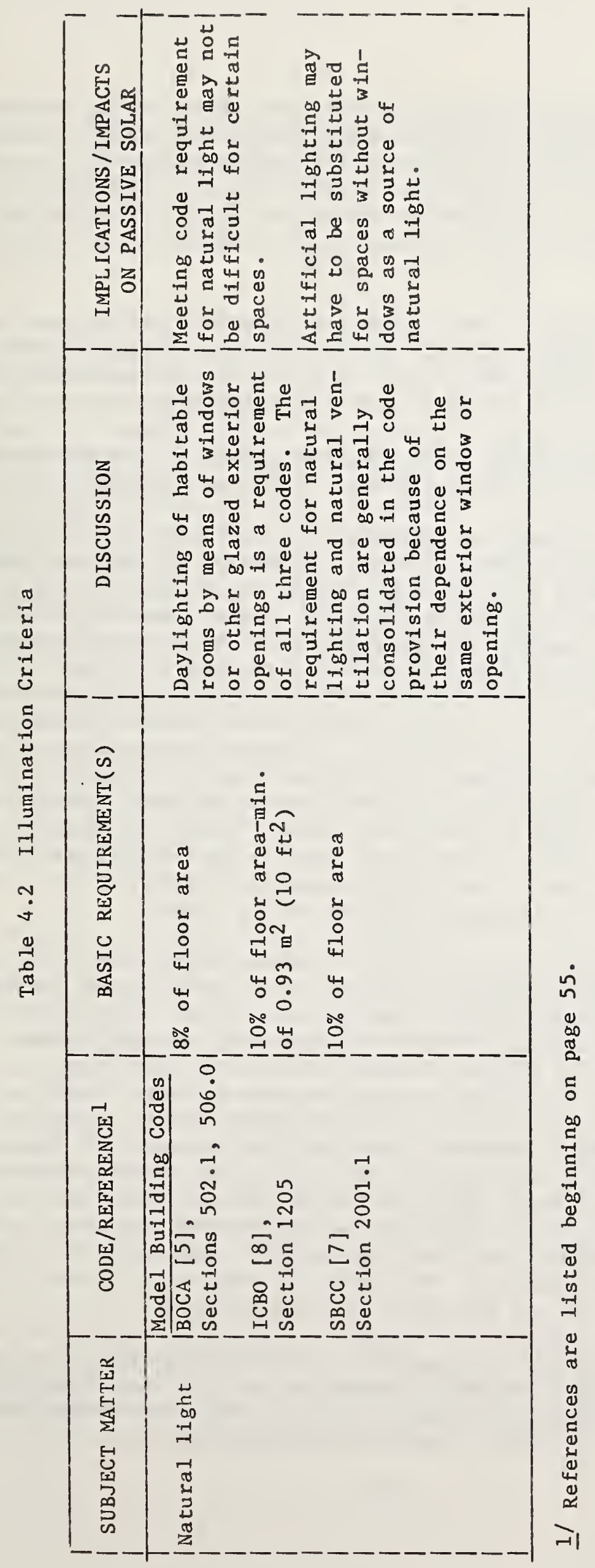


asymmetry of radiant ef fects are other factors that affect human comfort. (Asymmetry results when there is a large unbalance in the location and temperature level of radiant heating surfaces relative to the occupants of a space.) Conditions for human coinfort are given in ASHRAE Standard 55-81 [30] and are discussed relative to solar applications in section 2.1 .5 of reference [31]. Purchasers of passive solar houses expressed strong satisfaction with the comfort of their houses in a recent survey [29].

Radiant heat energy from wall or floor surfaces in passive buildings can be a most confortable means of space heating (or cooling in the case of heat loss to surfaces). Discomfort could result due to the effect of asymmetry if such wara radiant surfaces are counterbalanced by a cooling source such as a large expanse of glazing. Temperature stratification which is common in some passive techniques inay compound the health and comfort problems if temperature changes are not adequately matched to occupant comfort needs and schedule of activity.

Although the human body can adapt to extreme environmental conditions, it is evident that thermal discomfort very closely follows physiological strain. The role of temperature extremes in producing discomfort, incapacity, illness, and death has been studied over many years but still remains inconclusive. Ordinary seasonal change in temperature climates has an effect on the prevalence of illness. Most acute diseases and a number of chronic ones vary in frequency or severity with the time of year [32]. It would be speculative to closely link the health effects of indoor climate with that of outdoor climate, although there is always interaction between the two. However, this suggests that frequent changes in environmental conditions in some passive solar buildings may result in illnesses in a way similar to those resulting from seasonal changes. Natural passive indoor climate control more closely links the control of the indoor climate to that of the outdoors than does conventional space conditioning. Reference [33] provides a complete discussion of both outdoor and indoor climate effects on health including a comfort-health index.

Housing codes require that habitable rooms be maintained at specific minimum temperatures varying from $26^{\circ} \mathrm{C}\left(68^{\circ} \mathrm{F}\right)$ to $27^{\circ} \mathrm{C}\left(70^{\circ} \mathrm{F}\right)$ for thermal comfort. Some local codes refer to standards such as ASHRAE Standard 90-75 [34] which specifies $22^{\circ} \mathrm{C}\left(72^{\circ} \mathrm{F}\right)$ dry-bulb and $26^{\circ} \mathrm{C}\left(78^{\circ} \mathrm{F}\right)$ if air conditioning is used. Some passive designs operate with greater temperature fluctuations than are allowed by these standards and therefore may be constrained by them. There may be inconsistencies in the interpretation of what constitutes a habitable room. For example, solar atriums, sunspaces, etc., may be intended for seasonal or transitory use and specific requirements may not apply. Mass storage walls and water storage walls or roofs may provide for comfort conditions as radiant heat sources but with cooler air temperatures than may be required. Also, ASHRAE Standard 90-75 does not take into account the variation in comfort requirements that are influenced by the number of people in a space, the activities ongoing, and the age and health of the occupants.

The different bullding design requirements raise questions for a variety of building types that may have varied occupancy patterns. Many commercial buildings are not occupied during night hours when the most severe heating loads are likely to occur. This raises the question whether minimum thermal 
requirements for human comfort must be met during vacant times. Decentralized and passive heating and cooling systems, which are designed to provide comfortable thermal conditions with changing occupancy loadings, cannot be appropriately regulated by requirements that have been written for centralized mechanical systems which provide a constant thermal condition.

\subsubsection{Humldity}

Excessive levels of indoor humidity can be a problem in tightly sealed buildings and may further compound the above concerns about elevated temperatures. Passive solar greenhouses may add to humidity levels although there is not adequate evidence to support the frequently stated concern for this condition.

The role that relative humidity plays in human comfort is closely linked to the dry-bulb temperature and air movement. Effective temperature combines the effects of dry-bulb, wet-bulb, and air movement to give equal sensations of warmth and cold. This has been the best known and most widely used of all thermal indices. There is evidence that the upper limit for relative humidity frequently indicated on human comfort charts can be exceeded if sufficient air flow is provided in proximity to building occupants [35]. ASHRAE Standard 90-75 requires that if humidification is provided, it must be designed for a maximum relative humidity of 30 percent. Strict interpretation of this standard may constrain the use of "swamp" fans for cooling which are likely to result in greater than 30 percent relative humidity.

Givani cites wetness of the skin and thermal sensation as the two major sources of discomfort [35]. He also points out that, increased indoor relative humidity results in a significant reduction in respiratory illness during the winter. The suggested maximum rate of change of relative humidity is 20 percent per hour.

Excessive humidity can also create environmental problems in the form of mildew or fungus growth and condensation. Table 4.3 summarizes requirements for protection against decay and table 4.4 summarizes requirements for venting of attics. Passive solar techniques such as tightly sealed buildings, movable insulation, earth contact, cooling tubes, heated rock bins and solar greenhouses can create the potential for condensation and other humidity problems. Moisture from the uncovered earth is a significant contributor to condensation problems. Passive techniques such as envelope houses make extensive use of the earth in crawl spaces as a heat sink. In contrast to popular opinion, Ralph Johnson, President of the NAHB Research Foundation states, "the way houses are built today and in the last ten years does not result in a significant condensation problem [36]. Burberg refutes this, saying that condensation is becoming more common and ..."condensation is widespread and is costing millions in remedial ineasures [37]."

Except for the deleterious ef fect of excessive humidity and condensation on many building components and human comfort, it is difficult to assess the level of any health effect. It is acknowledged that some people are particularly sensitive to the effect of humidity and, therefore, will be adversely affected. The role of humidity increasing the emission of formaldehyde from 


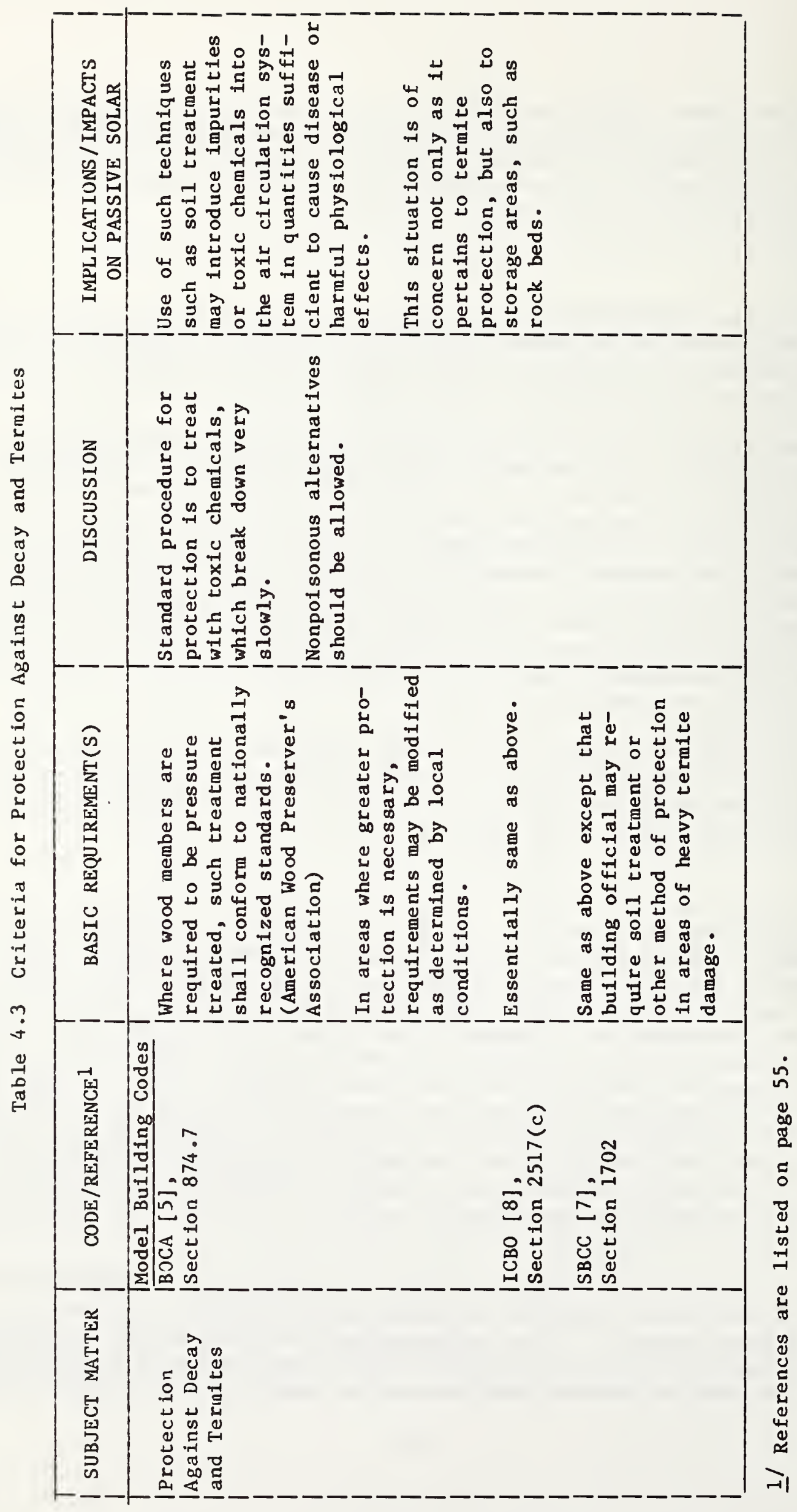




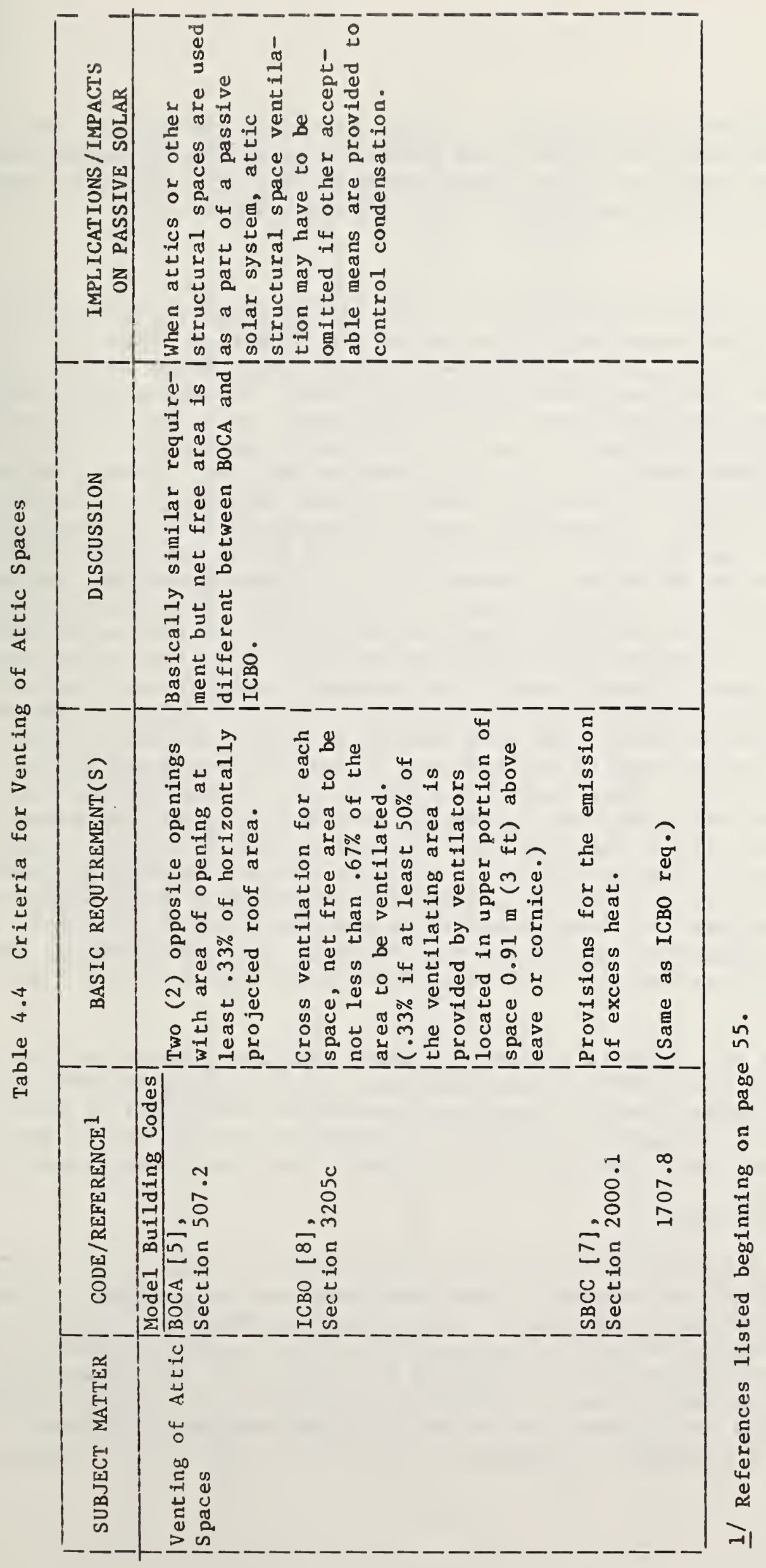


certain building materials and furnishings has been discussed in section 4.1.2. "Humidity, the one component of air that influences many physiological functions of the respiratory tract, can also change virus and bacterial survival times; thus, it could be a significant factor in respiratory health [33]."

4.2.4 Noise

Noise control is an environmental quality that can be closely associated with health. Uncontrolled noise can promote stress and interrupt sleep. It is beyond the scope of this report to discuss extremely high noise levels that have a more direct effect on health and hearing loss. Overwhelming evidence suggests that long, continued exposure to noise levels in excess of $85 \mathrm{dBA}$ is likely to degrade the hearing of a large percentage of humans [38]. This level (background levels-HC levels) is closely approached by many highways, expressways, railroads, and some industrial areas. Airport approaches may substantially exceed this level. Stenography and duplicating spaces are rated at 50 $\mathrm{HC}$ and computer rooms at $70 \mathrm{HC}$. (In the absence of octave band measurements, the $\mathrm{HC}$-numbers can be estimated by deducting 7 to 10 points from the dBA measurements in the space.) Ordinary glass is a rather poor sound barrier; thereFore, there is a concern for direct gain systems with major sources of noise from the south. A closed operable single window will typically provide less than $20 \mathrm{db}$ difference in noise level. Open windows providing ventilation for cooling will be an even more significant problem. Open planning for buildings to enhance energy distribution and hard surface materials frequently used in passive construction may add to the problems of noise transmission inside building spaces. On the other hand, the frequent use of massive materials, such as roof pond techniques, earth berming, concrete walls and the reduction of openings on most of the building perimeter can provide a distinct reduction in noise, all other things being equal. Multiple occupancies sharing common areas such as atriums for the capturing and dissemination of solar energy may be exposing themselves to noises generated in the common areas. However, the minimized use of mechanical systerns such as furnaces, air conditioning, and fans in passive systems greatly diminishes background noise within the building interior.

As shown on table 4.5 there is a consensus among building regulations that a sound transmission class (STC) of not less than 45 be required between tenant units and public areas. Most single glazed assemblies would fail to meet this requirement. Those techniques requiring air passages from the public space (corridors, atriums, etc.) may also have difficulty meeting these standards.

\subsubsection{Weather Tightness}

Passive solar techniques frequently modify the details as well as the concept of the exterior shell or envelope. These modifications are intended to improve the capability to collect (or reject), store, and distribute solar thermal energy. They primarily affect the south wall but some techniques affect other portions of the building envelope including the roof area. The health concern for these modifications is that the effort for achieving solar effectiveness not deemphasize the traditional role of the building envelope to provide security and protection from the elements and vermin. Reports and evidence 


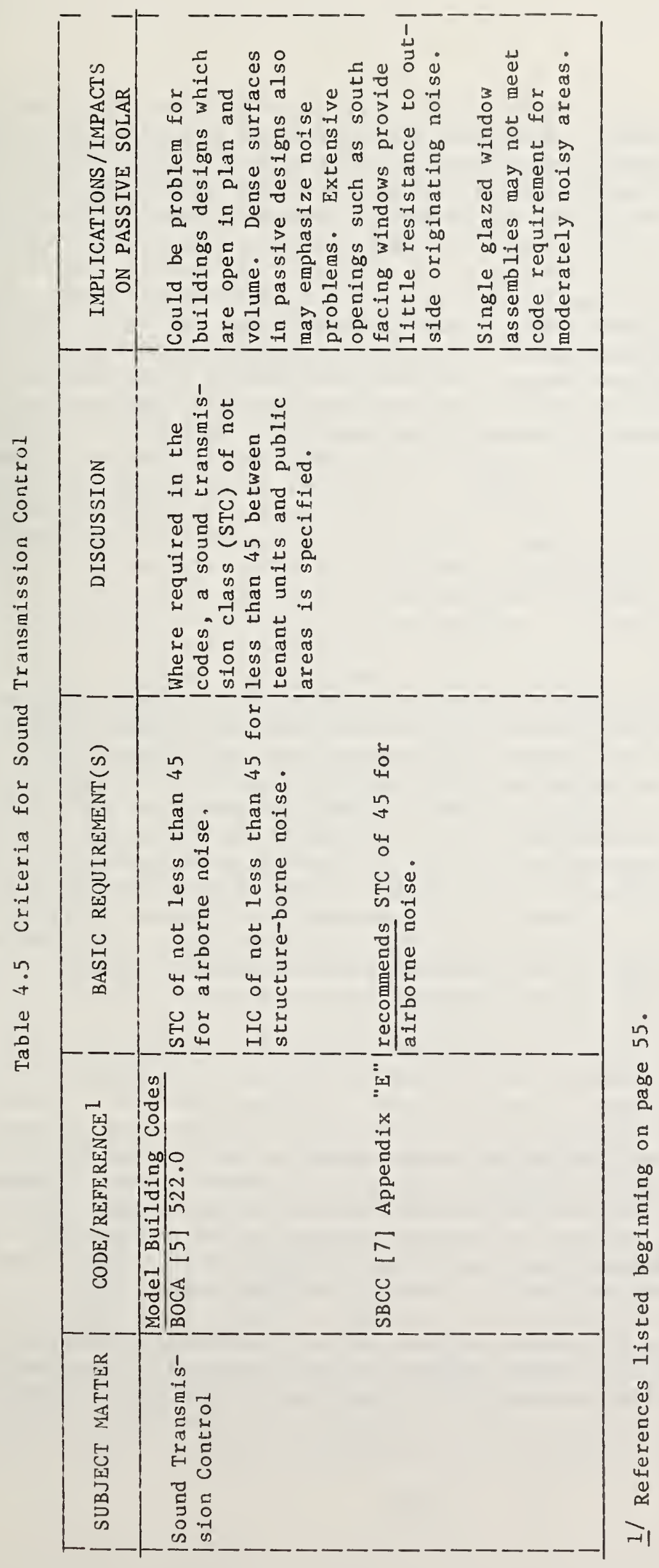


supporting this concern are limited and in most circumstances good practice could alleviate the problems. A January 1981 report of site visits to passive houses in the HUD residential demonstration progran stated that animals have penetrated the space between a Trombe wall and a warped glazing panel. In another instance, snow was stated as entering through a plywood return air duct. Many plastic films and sheets used for passive glazing expand and contract nore than conventional materials and degrade significantly during the weathering process. Wood framing members, as well as the glazing materials of some Trombe walls, solar attics, attached greenhouses and wall collectors are exposed to increased temperature, humidity, and perhaps ultraviolet effects when used in conventional settings. If materials such as these deteriorate under these conditions, the membrane may lose its integrity and expose the interior to outside conditions through penetrations such as ducts, chases, and vents. Many passive building devices such as double envelopes, cool tubes, heat exchangers, etc., create a number of crevices, convolutions and inaccessible spaces that can become trouble spots. The idea of a building shell as a systen of "filters" is a very sound concept but it requires of the designer additional attention to construction detail in order to ensure the building integrity as a shelter from exterior elements.

\subsection{FIRE SAFETY}

The fire safety issues of passive solar energy systems should be addressed in terms of the objectives of the fire safety contained in building regulatory documents. The primary fire safety objective of most building and fire regulations is to prevent the outbreak of unwanted fires and in the event of a fire, provide for the safe egress of the building's occupants. A secondary objective is to linit the spread of fire to adjacent buildings and properties. Finally, most building owners, if not the public in general, expect the requirerents to limit the spread of fire and related damage within the building of fire origin. Frequently this objective will be accomplished to some degree by meeting the prinary objective of fire prevention and life safety. The special requirements for the protection of buildings of high value, special risk, or historical importance will not be addressed in this report.

Although public education is of significant importance in preventing fires and reducing injury and life loss, the discussion here will be limited to those strategies normally employed in building and fire regulations to achieve fire safety objectives. The prevention of unwanted fires is achieved by controlling ignition sources and the ignitability of materials. Safe egress is provided by early fire detection, and providing a safe path of travel out of buildings by limiting the spread of fire and the generation and spread of toxic products of combustion. The spread of fire to adjacent properties is controlled by requiring separation distance between properties, limiting the flammability of exterior builaing components, and the use of firewalls and fire stops.

Some aspects of passive solar construction may be beneficial to fire safety. For example, the presence of large volumes of water such as in roof ponds or in water storage tanks can be helpful in firefighting if they can be properly tapped. Buildings in Monterrey County, California are required to have a minimum of 1000 gallons of water for firefighting purposes. County officials 
have given assurance that water used in the passive solar storage devices would meet this requirement. There is an indication that other counties have similar requirements, especially those that have frequent forest fires. The presence of this required water within the building envelope offers the possibility of its simultaneous use as thermal storage.

The general issues to be examined are control of ignition sources, ignitability of materials, spread of fire, exterior fire spread, material flammability, fire detection, means of egress, generation and spread of products of combustion, and energency access. Clearly some of these issues overlap. Passive solar buildings can reasonably be expected to be as safe as conventional buildings of similar type. Therefore, the fire safety issues will be examined for passive solar energy systens as they relate to available building and fire codes and other related regulations.

\subsubsection{Ignition Sources}

The prinary ignition source found in passive solar energy systems, but not normally found in conventional building designs, is the heat obtained from solar energy. There have been several fires in active solar energy systems as a result of the temperature attained in the collector. In one case which has been documented, the investigation concluded that combustible materials ignited after being exposed to moderately elevated temperatures for long periods of time [39, 40]. In another case, plywood in a collector turned into charcoal as a result of continued heating [41]. Charcoal of this type is believed to ignite at relatively low temperatures. This problem is complicated by a recent investigation which indicates that this charring of plywood may have been pronoted by fire retardant treatment. The ignition properties of such a material with fire retardant is uncertain. Additionally, the structural capacity of the material had been extensively degraded as discussed in section 4.5 .

Although the temperatures attained in active solar collectors are generally higher than those in passive systems, the designs may be similar. The collector in which the plywood turned into charcoal consisted of a single glass glazing, air space, flat black metal absorber, and a layer of plywood backed by insulation. The same materials can be found in passive solar systems.

The experience, to date, indicates that the most likely configuration for material ignition by solar heating consists of a directly irradiated, glazed, dark absorber surface in contact with a combustible material which is well insulated on the back side. The temperatures at which materials will ignite when exposed to moderately elevated temperatures for long periods of time are difficult to determine. For example, the most commonly quoted ignition temperature of wood is on the order of $200^{\circ} \mathrm{C}\left(392^{\circ} \mathrm{F}\right)$ although there have been cases where wood was ignited after continued exposure to temperatures thought to be slightly greater than $100^{\circ} \mathrm{C}\left(212^{\circ} \mathrm{F}\right)$ [42]. The ignition temperatures of plastic varies widely, ranging from lower than wood to much higher. Table 4.6 summarizes requirements in building regulations for "clearances from heated surfaces." 


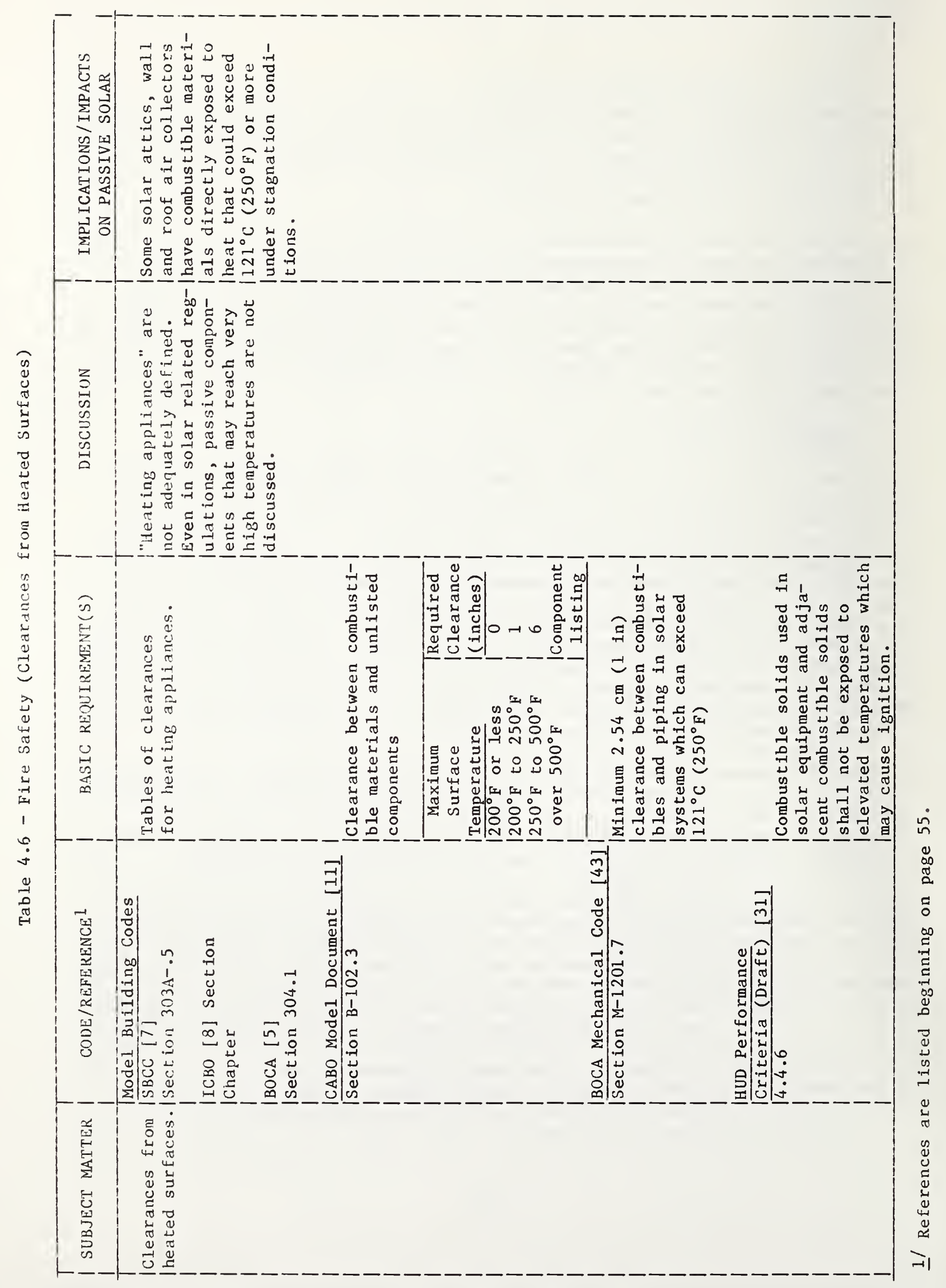




\subsubsection{Ignitability of Materials}

Although a number of tests have been developed to measure the ease of ignition of materials, they have not generally been incorporated into building regulations. Instead, test methods which measure the tendency for materials to spread flame are more prevalent in codes. In addition, one can minimize the intensity of a fire by limiting the amount of exposed combustible inaterial. Building regulations do not generally limit the amount of such materials which are not part of the building construction (e.g., furniture). They do classify materials which are part of the building by specifying limits relative to building use, type, and zoning requirements. The amount of some combustible materials such as interior finish is controlled by again limiting the tendency for those materials to spread flame.

\subsubsection{Spread of Fire}

Preventing the spread of flame in structures is usually accomplished through two techniques; providing barriers to the spread of flame and limiting the so-called flammability of materials.

Barriers against the spread of fire may take a number of forms. The most common are walls, floors, ceilings and other building assemblies with fire resistance ratings, the protection of openings through these assemblies, and firestopping. In addition, many of the requirements typically imposed on ventilation systems could be considered a type of fire barrier. The primary concern in passive systems with respect to fire barriers, is the use of unrestricted vertical and horizontal passageways for air travel. The passageways can take many forms including openable space between a solar greenhouse and a building, plenums between atriums and buildings, and the wall cavity within double-envelope construction.

Regulatory requirements for these air passageways, summarized in table 4.7, depend to a great extent on whether the air passages are treated as open or concealed spaces within the building or as air ducts or plenums. In general, the use of uninhabited basements, cellars, crawl spaces, cavity walls, areas above ceilings or attic spaces as supply air make up, exhaust air, or return air plenums or ducts is currently prohibited because they are considered as concealed spaces. Regulations require that concealed vertical and horizontal spaces be firestopped between stories and between bullding subdivisions. In addition, many occupancy classes other than one- and two-family dwellings require that the building be divided into areas each of which is separated from other parts of the building by fire resistance rated assemblies. These would typically include fire resistant rated floor-ceiling assemblies and wall assemblies to maintain the maximum area per floor allowed by the regulation. Unprotected passageways for air between these spaces would be precluded. Air ducts with fire doors or dampers are generally required for penetration of a fire resistance rated assembly. In addition, ducts which penetrate two or more floors in other than one- or two-family dwellings, must be enclosed in a fire resistance rated shaft. 


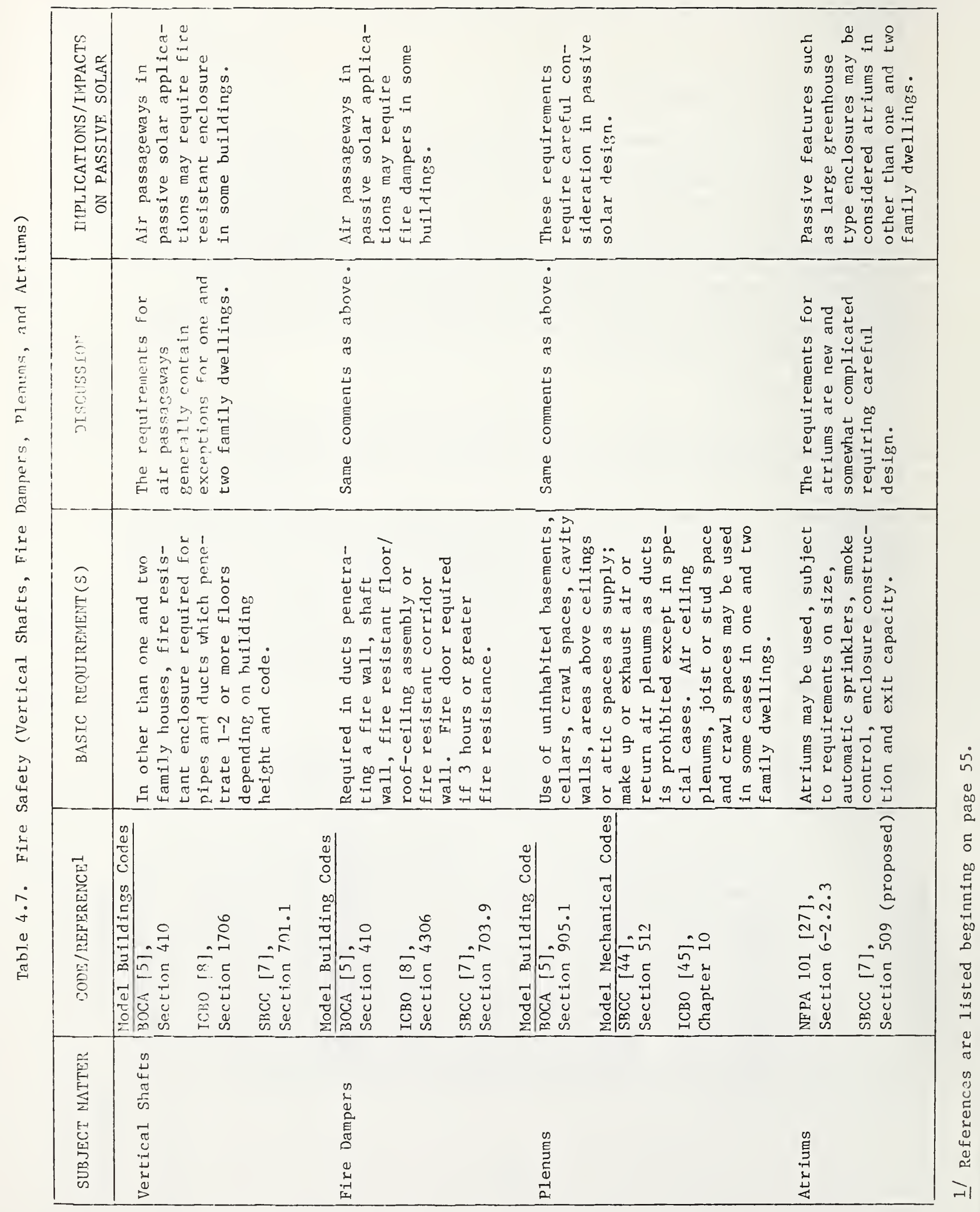


A special kind of shaft or vertical opening between floors is an atrium. Several model building codes have added requirements for atriums which require that it be enclosed in fire resistant construction, contain a smoke system, and that the building containing the atxium be protected with an automatic sprinkler system. The required enclosure of the atrium would require fire dampers for air passageways between the atrium and other parts of the building.

Firestopping requirements in building regulations are summarized in table 4.8 . The Recommended Requirements to Code Officials for Solar Heating, Cooling and Hot Water Systems [11] is the only document to specifically recognize that building code requirements conflict with some passive designs. Commentary in this document states that:

"1. 'Firestopping' may be omitted in concealed spaces in combustible construction when smoke activated fire dampers are installed to cut the vertical draft opening at each floor level in walls and at each support in roofs.

2. 'Firestopping' may be omitted in concealed spaces in noncombustible construction when smoke activated fire dampers are installed at each supply and return air opening. All wall cavities (concealed spaces) In excess of 200 square inches shall meet the requirements of a vertical shaft as indicated in appendix $\mathrm{XB}-1$.

Exception: In exterior walls only, the exterior wall of the shaft need not meet the vertical shaft requirements."

One aspect of fire barrier design unique to passive solar systems is the use of thermally massive walls, floors, and cellings to absorb and store heat. In some cases, these building assemblies may have increased fire resistance over those dictated by normal design, while in other cases, fire resistance may have decreased. Alternate wall, floor, and ceiling designs should first be analyzed in terms of conventional design criteria to determine fire resistance ratings. Often, alternative passive solar designs are conventional designs applied in unusual ways. However, acceptance of some alternate wall, floor and ceiling designs may involve testing to meet the fire resistance requirements of the codes.

\subsubsection{Exterior Fire Spread}

The objective of the requirements for exterior fire spread is to prevent the spread of fire from one building to another. It is accomplished by limiting the combustibility of the building exterior party walls, or providing separation distance between buildings. Generally, there are separate requirements for exterior walls and roofs. Passive solar systems frequently utilize unique wall and roof constructions making particular use of light and heat transmiting materials. This construction may present challenges in providing sufficient exterior fire protection. Good southern exposure often requires a greater distance between buildings or building apertures (such as found on the roof) to the south. This may prove to indirectly solve the problem of exterior flame spread through separation between buildings. 


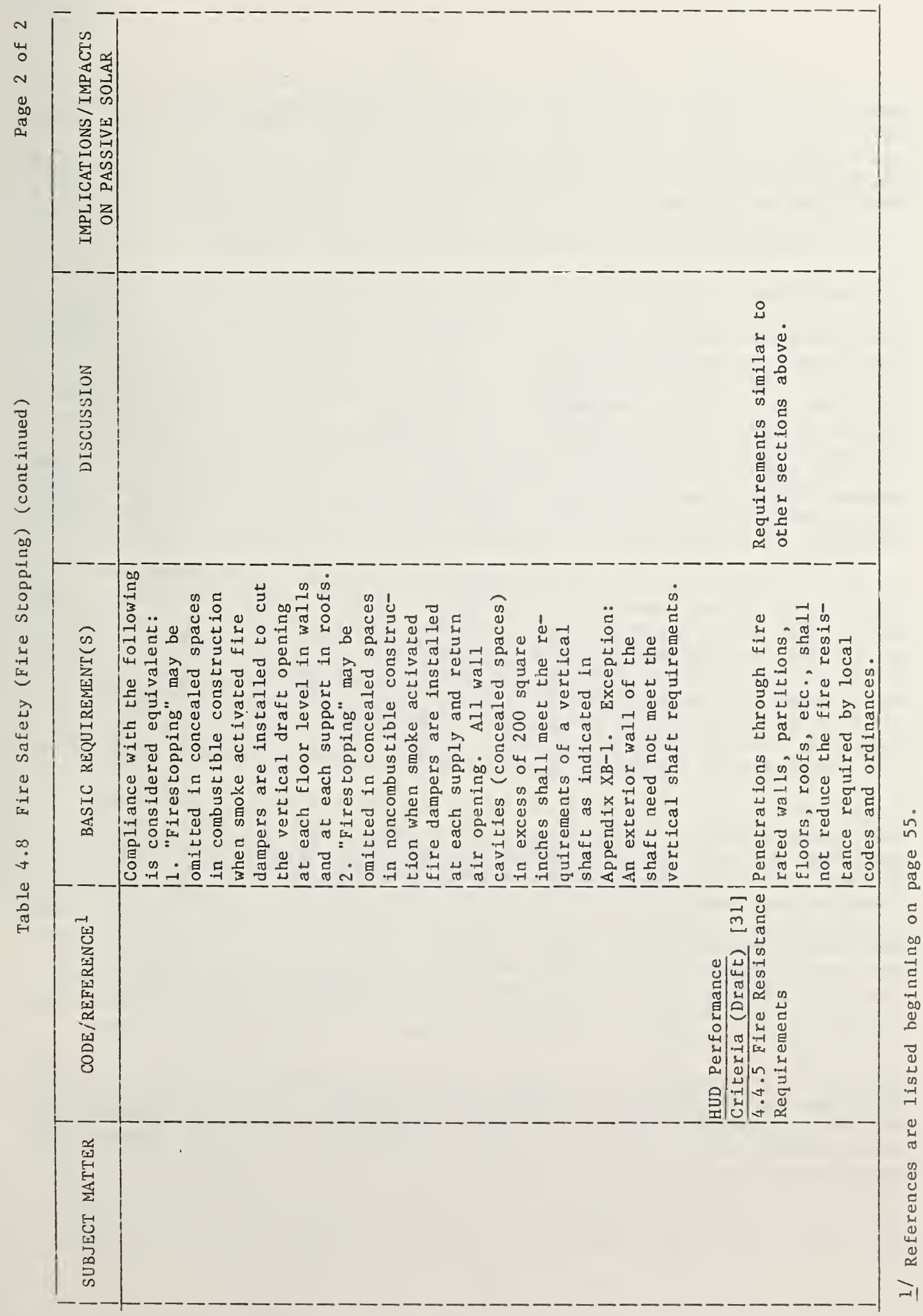


The requirements for fire resistance of exterior walls and wall openings are based on the occupancy type of the building, the distance to property lines of other buildings, and, often, the zoning requirements. Exterior walls of buildings located closer to the property line than a specified minimum distance are required to have increased fire resistance or the elimination of openings. Plastic glazing and approved plastic wall panels without a fire resistance rating may be used in exterior walls subject to limitations based on class of plastic, fire separation, and the area of the plastic relative to the wall.

The requirements for the fire protection of exterior roof coverings depend on the type of building occupancy, the separation distance from other buildings or lot lines and whether or not the building is located within the fire limits. Fire limits are designated areas in a local jurisdiction for the purpose of controlling the construction and use of buildings to prevent conflagration from fire. Fire limits are usually designated in areas containing congested business, manufacturing, and industrial buildings. Buildings required to be of fire resistant construction and those located within the fire limits are generally required to have the highest level of roof fire protection. In some instances high sloped roofs may be required to meet the fire resistance requirements of walls. This may restrict passive techniques where roof related solar apertures are sloped steeply to provide for the correct angle to the sun.

The use of light transmitting roof panels or skylights is of particular significance in many passive solar designs. Regulatory requirements for light transmitting roof structures differ somewhat between the documents evaluated and are all fairly complex. The requirements are different based on whether the material is glass or plastic. In most cases, glass skylights are required to be glazed with wired or tempered glass or plain glass with a protective screen. Although there is generally no maximum area for skylights there may be a maximum area for individual panels of glass. Areas may be limited due to roof access for firefighting and safety of the occupants on the interior.

Plastic roof panels are structural panels and may generally be installed in buildings where the roof is not required to have a fire resistance rating. Depending on the type of plastic and the regulation to which the building is designed, individual panels cannot exceed $9 \mathrm{~m}^{2}\left(100 \mathrm{ft}^{2}\right)$ to $27 \mathrm{~m}^{2}$ (300 $\mathrm{ft}^{2}$ ) with a maximum aggregate area of 25 to 33-1/3 percent of the floor area. Individual panels must be separated from each other by a minimum of $1.22 \mathrm{~m}$ ( $4 \mathrm{ft}$ ). Panels must not be installed closer than $1.83 \mathrm{~m}(6 \mathrm{ft})$ to $2.44 \mathrm{~m}(8 \mathrm{ft})$ from an exterior wall required to have a fire resistance rating. The requirements for plastic skylights are similar to those for roof panels except skylights are required to be mounted on curbs constructed $10 \mathrm{~cm}$ ( $4 \mathrm{in}$ ) above the roof. See table 4.12 for a summary of glazing requirements in building regulations.

The primary test method used in evaluating light transmitting plastic is ASTM D635, Standard Test Method for Rate of Burning and/or Extent of Time of Burning Self-supporting Plastics in a Horizontal Position. There are no studies known which correlate the results of the small scale tests with actual building fire performance. 


\subsubsection{Material Flammability}

The material flammability concerns of most importance to passive solar energy systems are those related to interior finish materials and duct linings and coverings. Interior finish materials are usually classified in accordance with test method, ASTM E84, Surface Burning Characteristics of Building Materials. Table 4.9 is a summary of related requirements in building regulations.

The requirements for interior finish materials vary greatly depending on occupancy and location of the materials within the occupancy. A primary concern with the use of interior finish materials in passive systems is with materials used for insulation. Unlike conventional construction, some passive systems may involve the extensive use of insulation within the structure rather than around the perimeter. Exposed insulation other than plastic foam will generally have to meet a requirement of an interior finish for the given location. The requirements for foam plastics are more specific. Foam plastics which have a flame spread of 75 or less may be used when fully protected by a thermal barrier of fire resistive materials having a finish rating of not less than 15 minutes. One-half inch thick gypsum board will normally meet this requirement. Foam plastics with flame spread of 25 or less may be used in certain cases when covered by an aluminum or steel sheet and the insulated area is protected with automatic sprinklers.

Regulatory requirements for movable insulation including special drapes and interior shutters are not clear. If the insulation is considered part of the building, then it may have to meet requirements of an interior finish. If the insulation is considered $a$ trim and is not in excess of 10 percent of the total wall and ceiling area, then a less stringent requirement would be imposed. Since plastic materials are desirable for much of this insulation, it may be necessary to study the actual fire performance of typical insulation configurations.

Duct coverings and linings have separate flame spread requirements. In oneand two-family dwellings, duct coverings and linings must have a flame spread rating not over 25 to 50 depending on the building regulations. In other than one- and two-family dwellings, duct coverings and linings must have a flame spread rating not over 25. Ducts are generally required to be constructed of approved materials such as steel, iron, aluminum, concrete, or approved fibrous glass. Return ducts of materials no more flammable than one-inch boards may be used in one- and two-family dwellings.

\subsubsection{Fire Detection}

The primary concern in the area of fire detection for passive solar systems would appear to be the location of sinoke detectors in residential occupancies, particularly one- and two-family dwellings. It is generally recognized that smoke detectors shall be placed in hall areas leading to rooms used for sleeping purposes. In cases where unusual air movement is involved, additional detectors or alternative locations may be necessary. In residences with passive solar systems, particularly designs like the envelope house, alternative paths for smoke travel may be present. These paths may permit smoke to reach the sleeping 


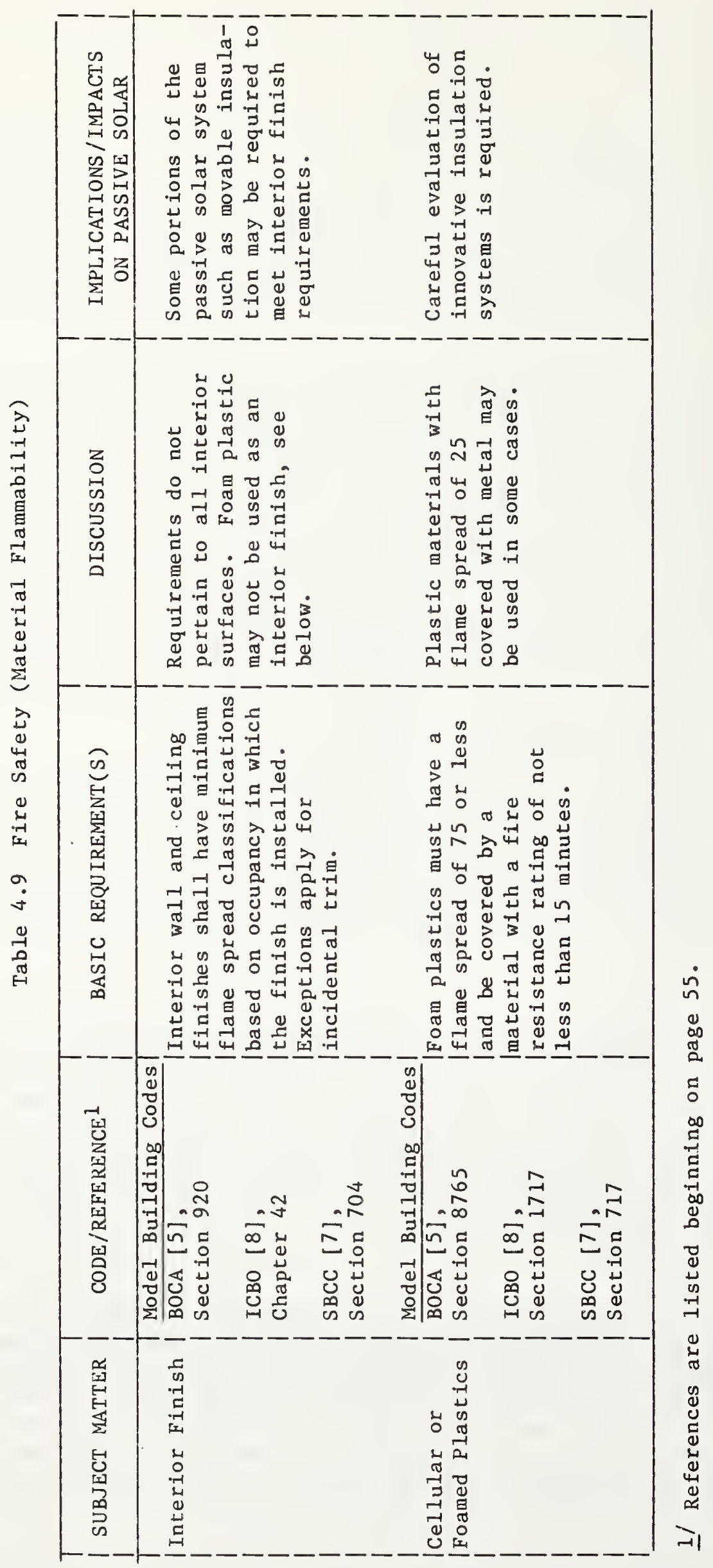


areas without entering the hallway and activating the smoke detector. An example of this situation would be where windows in sleeping areas open to an inside area such as an atrium or greenhouse.

\subsubsection{Means of Egress}

Means of egress requirements summarized in table 4.10 can be readily incorporated into most passive solar designs if their consideration is given during the design stage. The exit requirements for one- and two-family dwellings may be of particular concern in the design of some passive systems. Most building regulations require two means of escape from every bedroom, at least one of which must be a door or stairway leading to the outside of the building at ground level. Traditionally, the second means of escape has been provided by a door or window leading directly to the outside of the building. Many energy efficient and passive solar buildings' designs seek to eliminate windows in north-facing bedrooms. Several model building codes now permit the second means of escape to be a door or stairway providing a means of unobstructed travel to the outside of the building. Some do not require a second exit if the primary exit leads directly outside of the building at ground level and if the dwelling is protected throughout with an approved automatic sprinkler system.

\subsubsection{Generation and Spread of Products of Combustion}

Although it has long been recognized that the control of products of combustion is one of the most important fire protection strategies available, it has been one of the most difficult to implement. Most current regulatory requirements deal with limiting the visible products of combustion or smoke. Methods of measuring other toxic products of combustion are being developed. These measurement methods must then be coupled with criteria for the maximum acceptable level for these products and then be converted into regulatory requirements.

At present, the limited smoke development requirements are based on ASTM E84, Surface Burning Characteristics of Building Materials. The requirement of particular significance to passive solar systems are those for duct coverings and linings. The maximum smoke development rating for duct coverings and linings varies between 25 or 50 in regulatory documents depending on where the duct is to be used.

Special smoke control measures are required to protect egress paths from buildings. Control of smoke spread is frequently accomplished by the same barriers used to control fire spread. These usually consist of smoke-proof towers or enclosures. Smoke control requirements vary widely depending on the regulations and type of occupancy. Although smoke control is not required in one and two family dwellings and many small commercial buildings, consideration should be given to the smoke movement risks associated with many passive designs. Passageways designed for the movement of heated air throughout the building may also be very efficient at moving smoke. Passive systems generally utilize large air passageways and are designed to take advantage of natural convection both of which may be an aid to rapid smoke movement. There are no standards for installation of smoke control systems in one- and two-family dwellings and the 


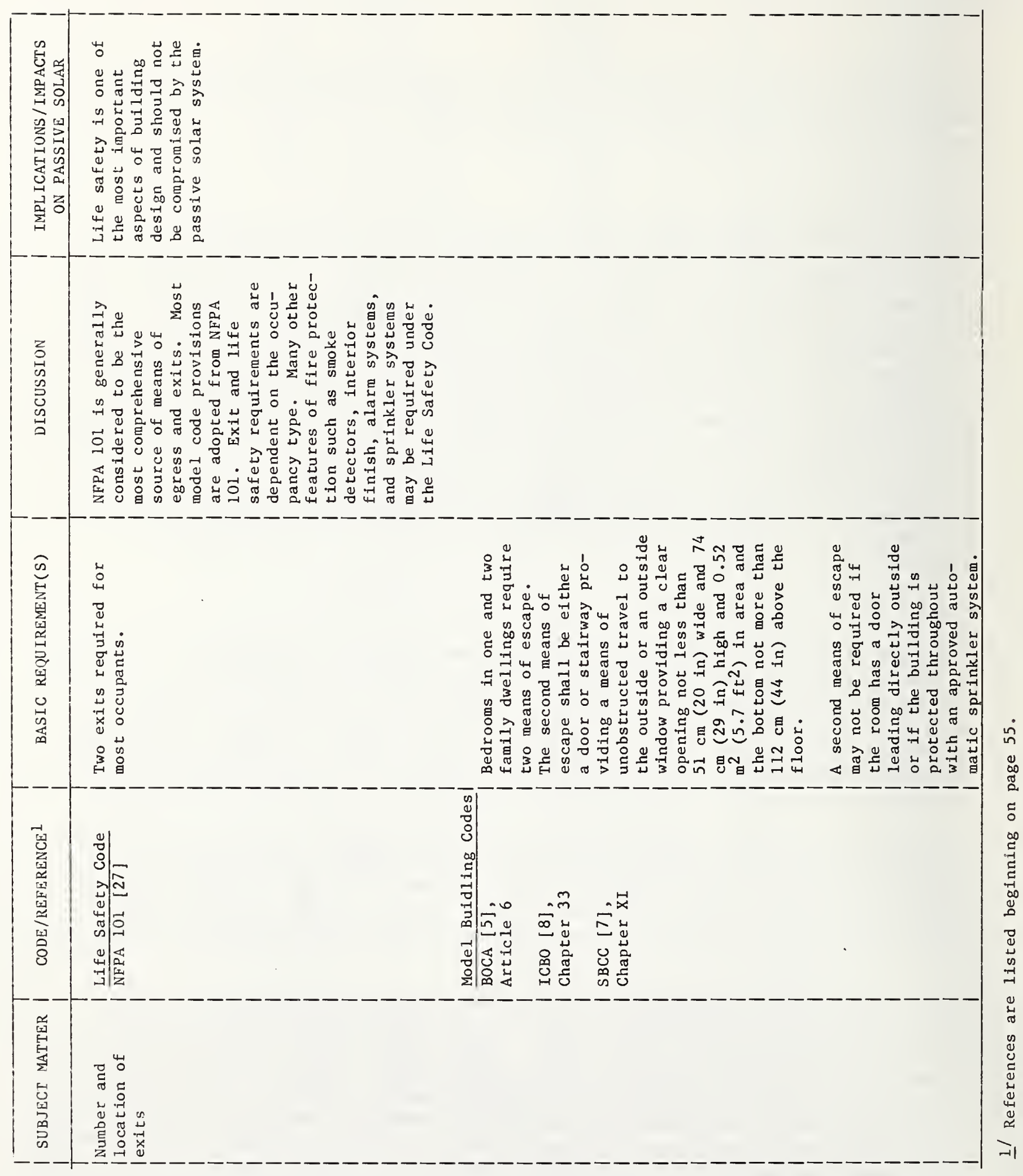


wide variety of passive designs indicates that the smoke control system must be designed for the particular application. The primary objective of smoke control is to protect means of egress and may be integrated with the smoke detection system. In some passive solar buildings, there may be a possibility of linking a smoke control system with the heat exhaust or passive ventilation system.

\subsubsection{Emergency Access}

The primary consideration in passive systems relative to emergency access is firefighter education. As a result of their design, passive buildings may be similar in appearance to conventional construction even though they may contain unconventional paths for sinoke and fire travel. Commercial and industrial buildings are usually inspected by the fire departments in medium and larger cities. During these inspections, the features of the passive system which affect firefighting tactics can be noted. However, one- and two-family dwellings are rarely inspected and the fire department may not be aware that a house has a passive system. Features such as double walis and roofs, and building components which serve as air passageways may hamper rescue efforts and delay location and control of the fire.

\subsection{STRUCTURAL CONSIDERATIONS}

Some passive solar buildings have construction details which are not that common in conventional structures. These include: (1) large glazed spatial areas on the building exterior concentrated on the south-facing side; (2) thermal mass (e.g., roof ponds, water-filled columns, concrete block walls) located within the interior of the building for the storage of energy; (3) excavations adjacent to the foundation for the placement of storage tanks, underground piping, etc.; (4) large open interiors used as greenhouses, atriums and solariums; and (5) earth covered structures. Structural design procedures are sufficientiy well developed to provide for the safe utilization of such features. Loadings, desiccation of wood, and glazing considerations will be discussed in some detail below.

\subsubsection{Loadings}

Table 4.11 presents a sumary of structural design criteria contained in current building regulatory documents. The design of passive solar constructions should be easily accommodated within these criteria. Special consideration is needed for solar retrofit situations when thermal mass is added within the existing structure which has an unknown load capacity. Generaliy, this includes the large amount of mass which is present in most passive buildings for thermal storage which may or may not be an integral part of the structure.

However, mass in the form of free-standing concentrated loads placed inside or adjacent to occupied spaces are not directly addressed in current building regulations. Large water containers weighing over $190 \mathrm{~kg}(417 \mathrm{lb})$ are frequently stacked, suspended, or placed vertically within the building envelope. This practice raises the issue of container stability. The frequent placing of these containers near large expanses of glass makes structural stability of these stacked units even more critical. Restraint from overturning of these 


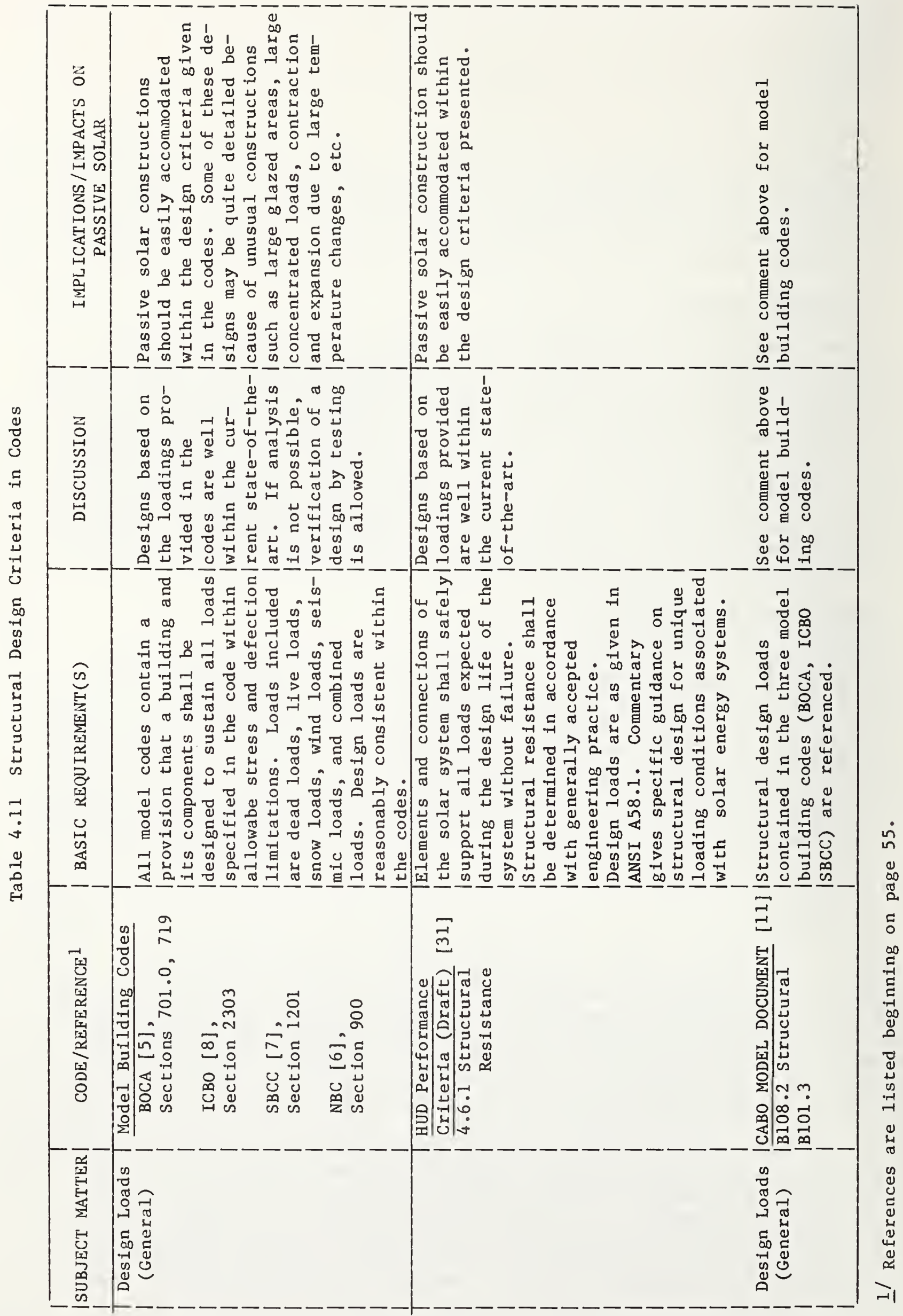


storage devices can be simply achieved but frequently is not provided. Buildings located in areas of seismic activity will potentially have a more severe problem. Water movement behavior and the tendency to "slosh" must be considered for the stability of large containers of water which could be affected by earthquake or other impact forces.

Earth covered structures are a type of passive solar design which provide some unique structural design considerations. Researchers at Minnesota University $[46,47]$ have analyzed code problems unique to this type of building and have identified the following structural design issues:

a. design loads on an earth covered roof may be five or more times greater than on a conventional roof;

b. completely buried walls must be designed to resist significant lateral forces (e.g., hydrostatic pressure);

c. soil tests may be required due to the high loads on earth covered houses;

d. waterproofing of below ground roof and walls found in this type of building is directly addressed in current codes;

e. design by a licensed engineer may be required even for conventional framed structures because of unique loading conditions.

\subsubsection{Desiccation of Wood}

A structural concern that is not addressed in building regulations and is somewhat unique to solar applications is the desiccation of wood support members. Prolonged exposure to elevated temperatures, on the order of $100^{\circ} \mathrm{C}$ $\left(212^{\circ} \mathrm{F}\right)$, significantly reduces the structural capacity of wooden members. Some passive solar techniques, such as solar attics and wall air collectors, expose wood structural and framing members to elevated temperatures. During periods of stagnation, when heat energy is not being removed from the collection area, temperatures can approach a level at which significant desiccation can occur. In general, the mechanical properties of wood decrease when heated and increase when cooled. This effect is immediate, but prolonged exposure at high temperature causes an irrevers lble decrease in properties. At a constant moisture cortent and below about $204^{\circ} \mathrm{C}\left(400^{\circ} \mathrm{F}\right)$, mechanical properties are essentially linearly related to temperature. Inberg has shown that, in compression, several species of wood lost 50 percent of their strength at a tenperature of about $106^{\circ} \mathrm{C}\left(222^{\circ} \mathrm{F}\right)$; the temperature-strength relation in the range from ambient to $100^{\circ} \mathrm{C}\left(212^{\circ} \mathrm{F}\right)$ being roughly linear [48].

A conclusion by McGuire states that if a long service life is desired, wood under service conditions should not be exposed to temperatures appreciably higher than $66^{\circ} \mathrm{C}\left(151^{\circ} \mathrm{F}\right)$ [49]. Exposed framing members may be supporting unusual dead loads, such as mass for thermal energy storage. In some cases, the presence of storage mass may form a heat sink and help to retard the maximum temperature to which wooden support members are subjected. However, the 
possible strength reduction of wood framing members caused by exposure to elevated temperatures, somewhat unique to passive solar applications, is a potential problem of which designer/builders should be aware.

Some recent occurrences seem to support this concern relative to wood dessication. One involves a "solar attic" and two others involve site built, active roof collectors. The solar attic house is located in California and is a solar demonstration project sponsored by the Department of Housing and Urban Development. Elevated temperatures have been recorded in the attic space as well as in the structural framing members. Under stagnation conditions (no air flow or venting) $81^{\circ} \mathrm{C}\left(178^{\circ} \mathrm{F}\right)$ was recorded in the attic when outside ambient was near $32^{\circ} \mathrm{C}\left(90^{\circ} \mathrm{F}\right)$. A temperature of $95^{\circ} \mathrm{C}\left(203^{\circ} \mathrm{F}\right)$ was measured $11.4 \mathrm{~cm}$ ( 4.5 in) into the wood of a rafter supporting the glazed roof which serves as the collector of this solar attic. The plywood flooring of the attic was badly cracked and partially delaminated. Gypsum wallboard on the vertical surface of the back of the attic was dried out and powdery. Also, lag bolts which fastened the glazing battens to the rafters were pulling loose.

Another investigation involved a site-built, active air system integrated into the roofs of condominium units in New Hampshire. Again temperatures of approximately $98^{\circ} \mathrm{C}\left(208^{\circ} \mathrm{F}\right)$ were measured well into the interior of rafters supporting the absorber plates of these air collectors. Foil faced insulation boards immediately behind the absorbers had surface temperatures of $105^{\circ} \mathrm{C}$ $\left(222^{\circ} \mathrm{F}\right)$ and $92^{\circ} \mathrm{C}\left(197^{\circ} \mathrm{F}\right)$ inside the board. Some discoloration was observed suggesting physical deterioration of the foam insulation. Attic temperatures were in excess of $65^{\circ} \mathrm{C}\left(150^{\circ} \mathrm{F}\right)$ even though the collectors within the roof plane prevented direct solar radiation into the attic. These attics extended over more than $76 \mathrm{~m}$ ( $250 \mathrm{ft}$ ) of open space. Building codes frequently limit concealed roof spaces to $279 \mathrm{~m}^{2}$ (3000 $\left.\mathrm{ft}^{2}\right)$ or less, or they must be subdivided with approved fire stops.

This occurrence suggests that joints and connections in wooden members may be especially vulnerable to the desiccation phenomenon. Metal elements used in such connections including nails, bolts, screws, and connectors may conduct elevated temperatures deeply into the wooden members. The resulting desiccation at these points may weaken the joint significantly and render the connection ineffective. As stated earlier, the wooden members themselves would be weakened at elevated temperatures but joints and connections are frequently the critical elements of a structural component. One conclusion is that collection spaces such as these either must not be allowed to stagnate or they must be built of materials that will withstand elevated temperatures. Shading of the structure, fail safe venting, careful detailing of joints, and connections are some techniques that should be considered.

Other investigations involve several site-fabricated, active liquid collectors in which the collector/absorber backing consists of $0.95 \mathrm{~cm}(0.375 \mathrm{in})$ to $1.90 \mathrm{~cm}(0.75 \mathrm{in})$ plywood sandwiched between thin sheets of copper and aluminum. These panels also serve as the only roof sheathing of the buildings. Investigations at several sites, notably in South Carolina, have shown that the plywood of some panels has been reduced to a charcoal appearance by the high 
temperatures and has lost structural integrity. This condition has been observed for at least ten other sites.

There have been some troublesome inconsistencies revealed in these investigations. There are cases where panels adjacent to severely charred ones have little or no discoloration. It has been suggested, and tentatively supported by Forest Products Laboratory (FPL), that fire retardant treatment may promote the charring and degradation of the plywood in such circumstances. Inadvertently, some panels may not have been treated with fire retardants. This raises the dilemma that fire retardant treatment may be a necessary precaution against potential ignition but may also promote the structural deterioration of these materials.

\subsubsection{Glazing Considerations}

Broad expanses of glass are frequently used in both conventional residential and commercial construction. Passive solar design practices tend to consolidate glazing on the south faces of the building, with significant reduction of windows on the north, east, and west sides. Often the total amount of glazing used in the building is not significantly increased over typical building design.

Glass is the most common glazing material used in passive solar, although a wide variety of plastic glazings are also used. Glass breakage constitutes one of the most commonly acknowledged physical hazards in residential buildings. Each year, in the United States, there are approximately 215,000 injuries involving glass breakage in residential windows [50]. The following applications, representative of some of the prevalent uses of glass in passive solar systems, may increase the hazard potential even above the normal incidence of glass related injuries: glass skylights and roof panels; sloped areas of glass; mass storage units adjacent to glass panels; glass installed very close to floor level; and glass installed adjacent to doorways and general circulation patterns. Large glazed areas are of particular concern in those parts of the country in which earthquakes are prevalent. There is a significant amount of seismic activity in the west and southwest where there is a strong interest in passive solar construction. Additional passive applications of glass that may have safety implications include: the use of multiple glazings, large temperature fluctuations (affects expansion and contraction, and potential thermal shock), and increased glare and reflection in the vicinity of the glazing.

The use of safety glass, such as tempered glass, laminated glass, or perhaps wire glass, will resolve most of the dangers associated with glass breakage. Careful attention to detailing and the use of restraining devices or rafls will also help reduce safety problems. Present building regulatory requirements offer adequate guidelines for these practices.

Regulatory provisions which relate to the structural design of glazing are summarized in table 4.12. Criteria considered are structural support of glass, human impact, wind loads and limits of glass area, sky light design requirements, and the design of plastic glazing. 


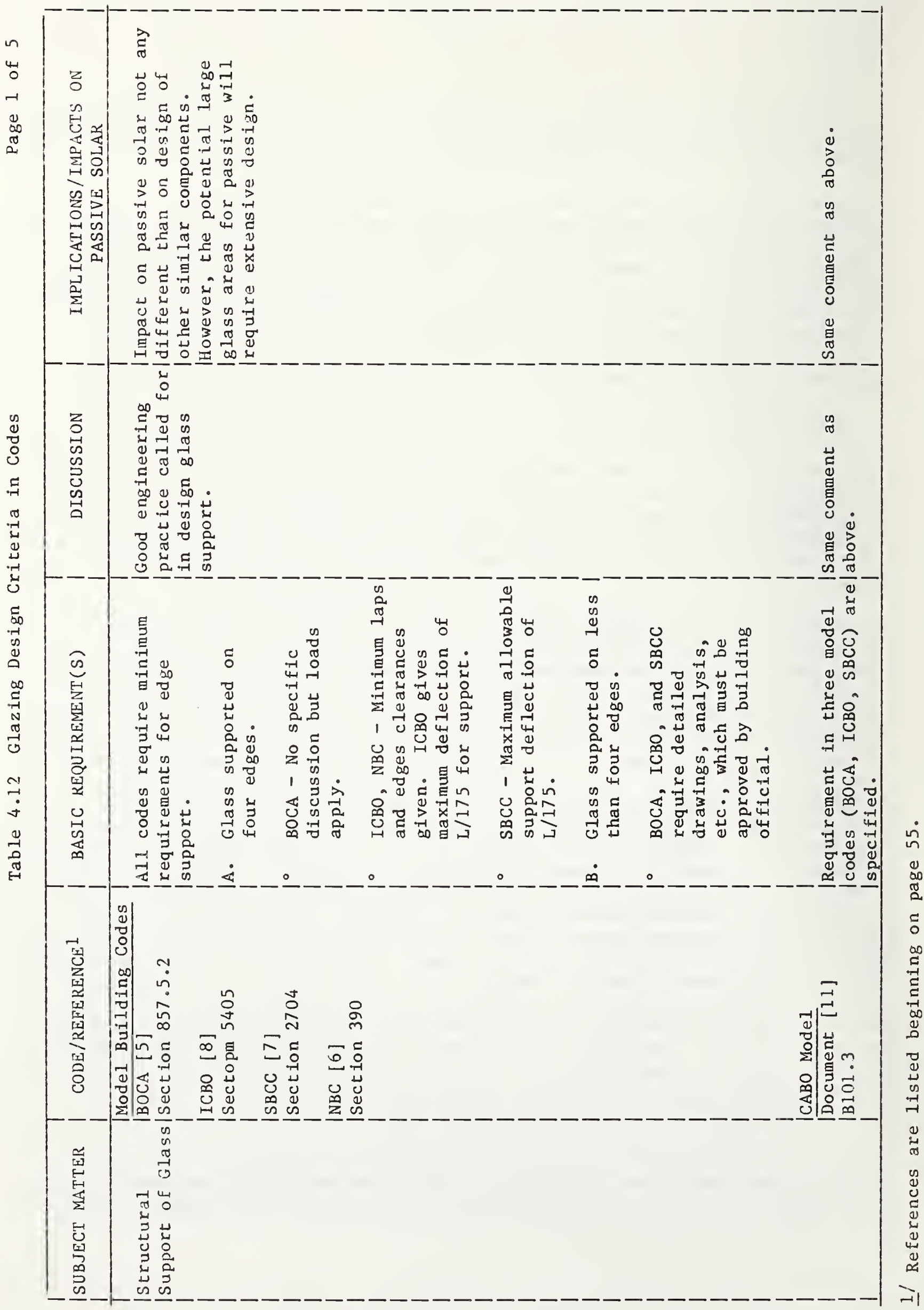




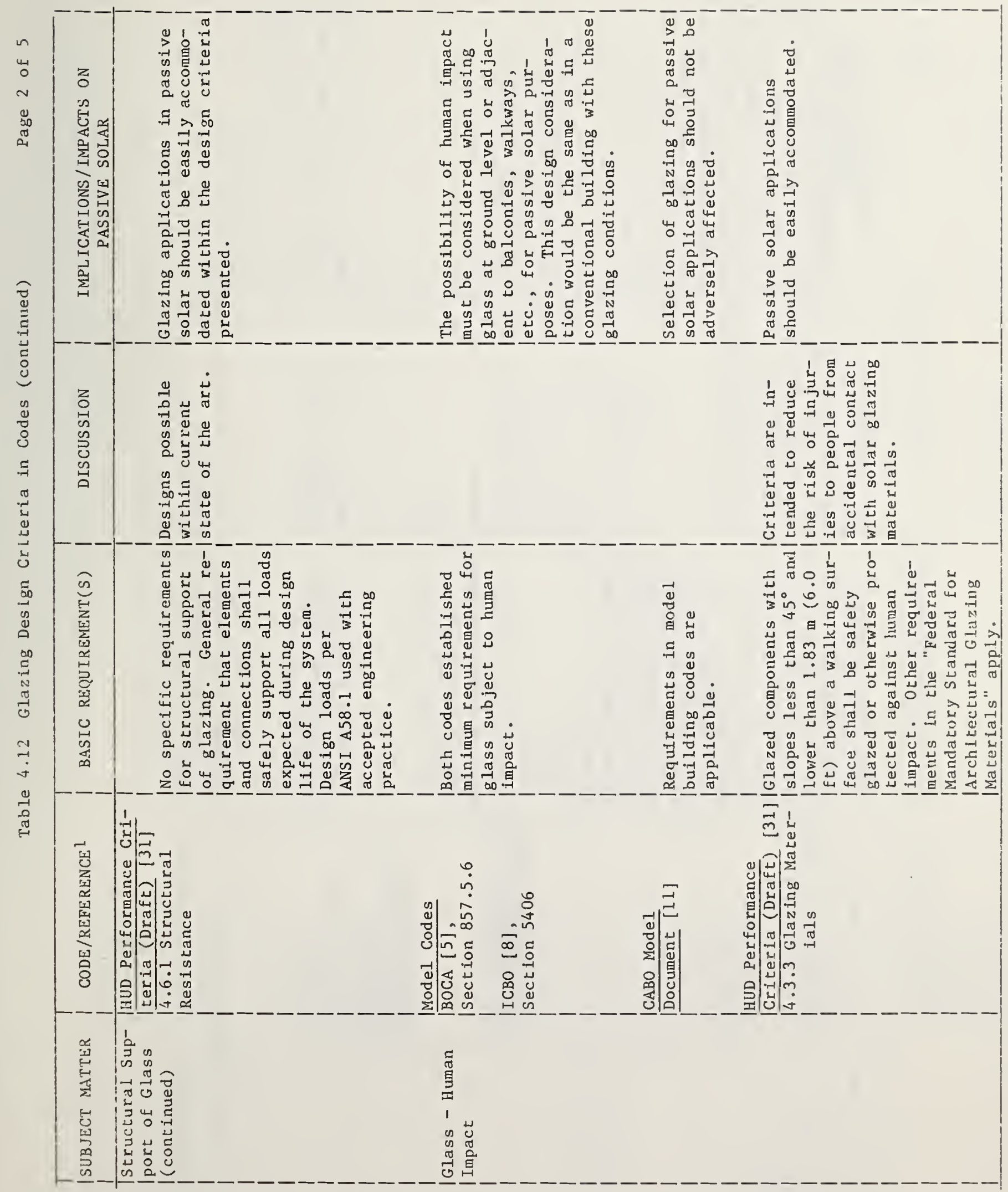

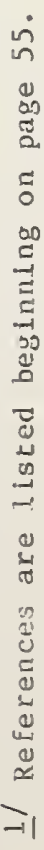




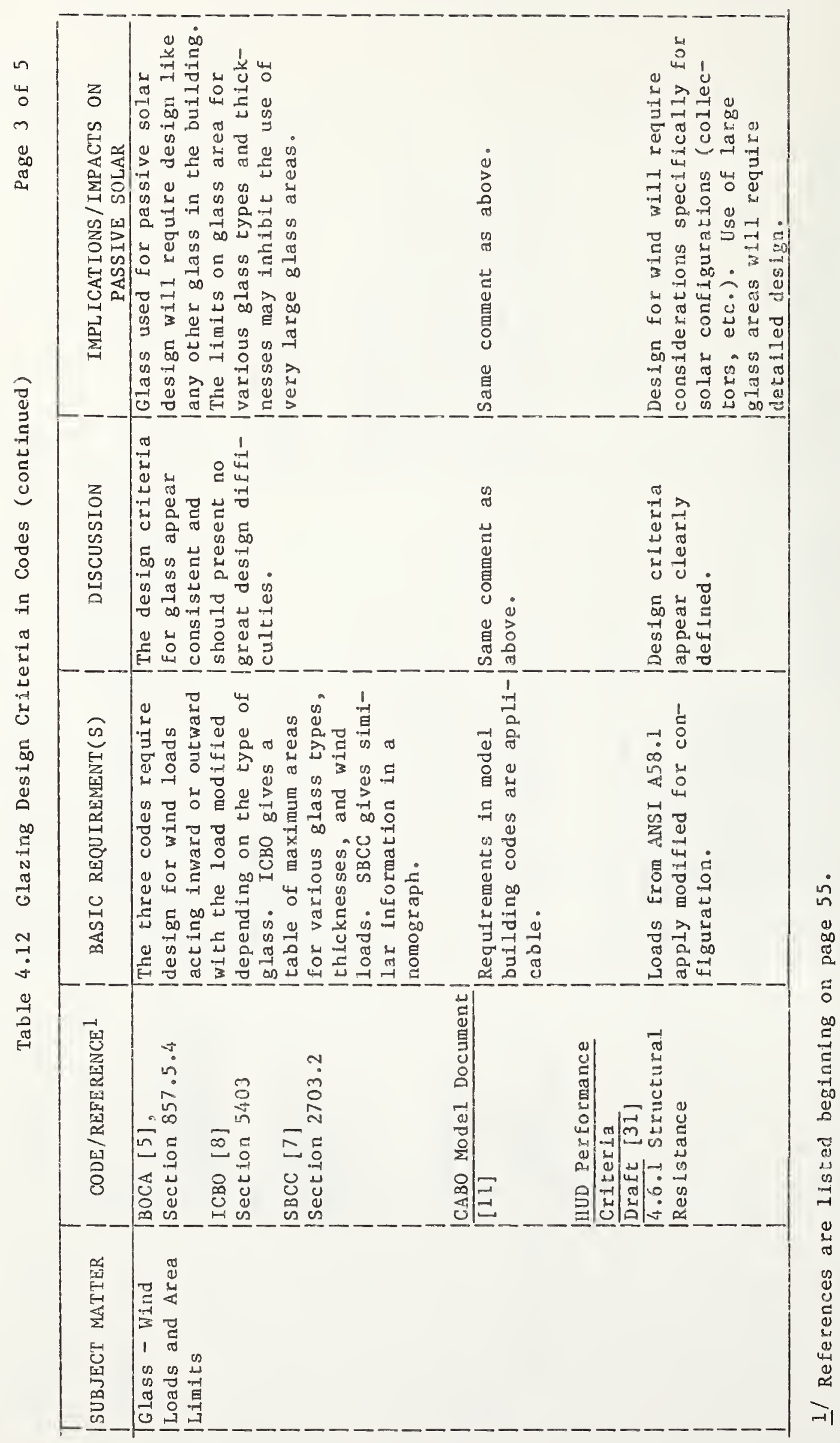




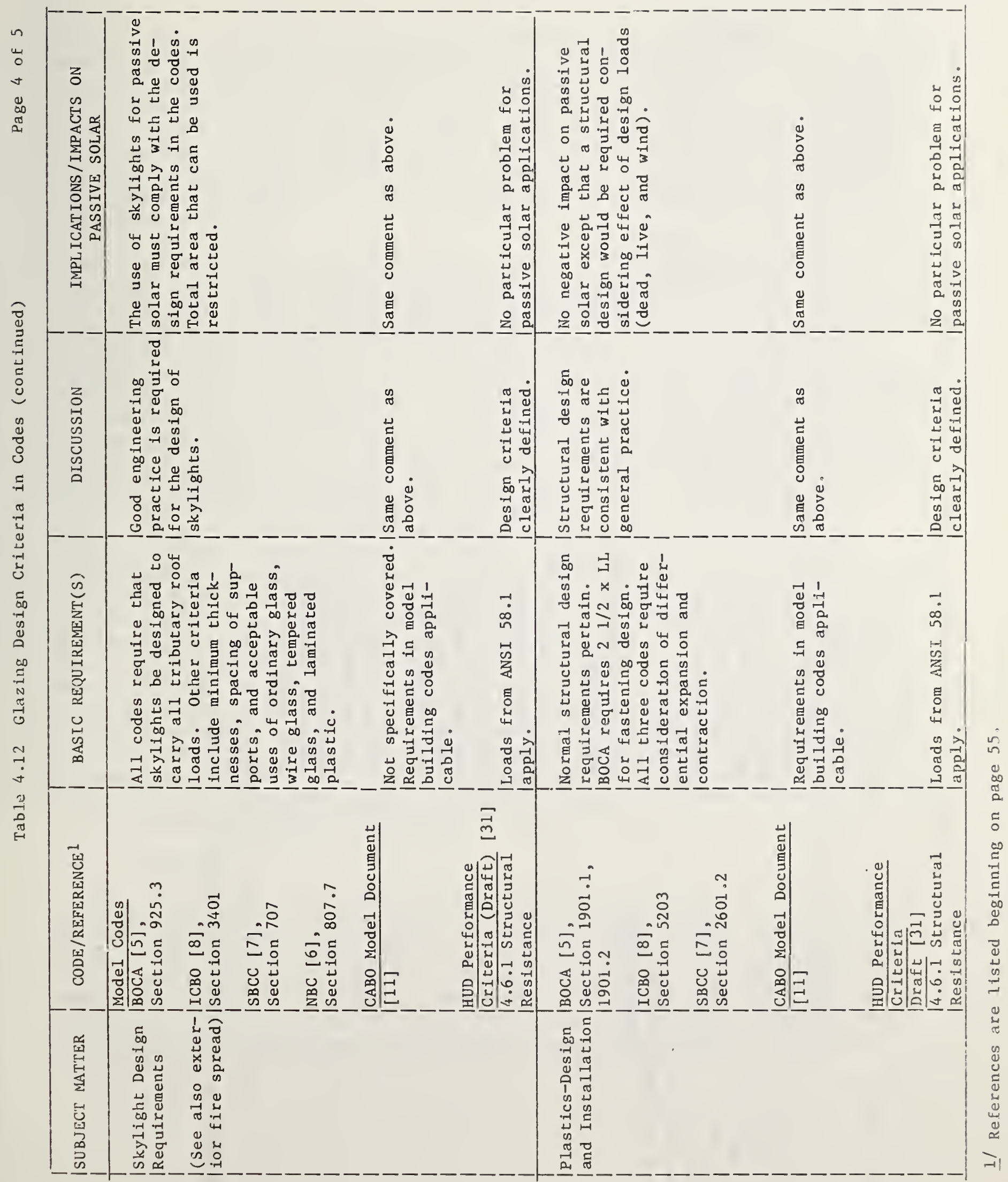




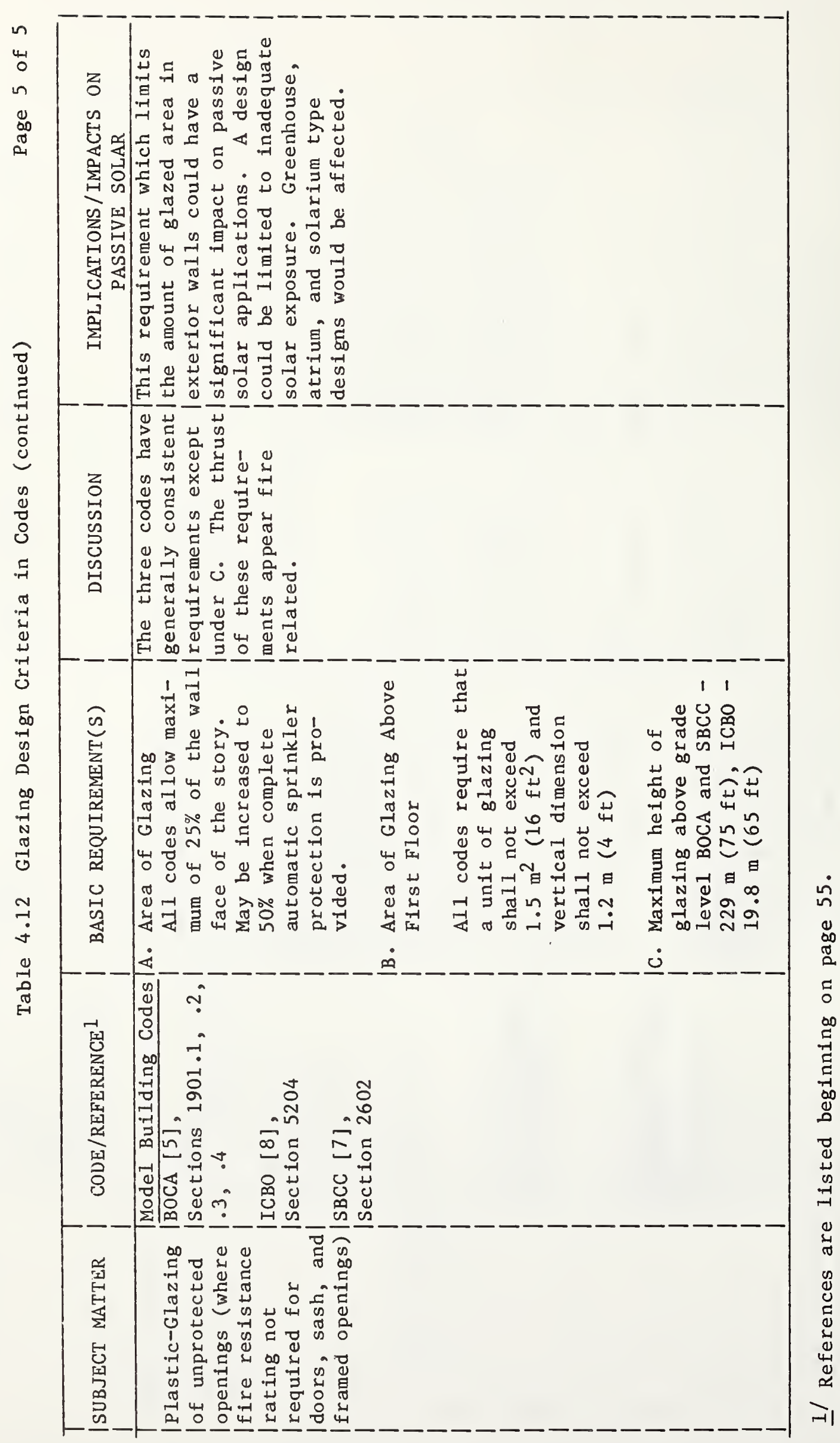


Provisions for structural support of glazing are generally presented as maximum areas depending on glass type, thicknesses, and design wind loads. This could constrain a passive solar designer who may want to use glass more extensively than regulations would allow and could require a greater level of design. For example, three of the model codes (BOCA, ICBO, and SBCC) specifically require that detailed drawings, specifications, and designs be submitted to the building official for approval when glass is used which is not supported along all four edges. The potential for injury due to impact of the glass should be thoroughly considered.

Glass used in skylights and roof panels creates an additional safety problem because of the hazard of broken glass falling into occupied spaces. Buildirg codes generally require that glass used in skylights be tempered or wire glass, or have screens installed both above and below the skylight. Skylights sloped less than 45 degrees must be on $0.1 \mathrm{~m}$ ( $4 \mathrm{in}$ ) curbs. Skylights must also be designed to carry all tributary roof loads. There has been some concern stated. that the presence of large areas of skylights would inhibit access and mobility of firefighters in an emergency. For this purpose, roof obstructions are frequently limited to $1 / 3$ of the roof area. The distinctions between skylights, glazed roof panels, and sloping facades which are glazed are not well characterized in building regulations and could lead to some confusion with unusual passive applications in determining compliance.

Safety glazing is required for the glazing of entrance doors and for panels adjacent to entrances and walkways if the panels are larger than $0.46 \mathrm{~m}$ (18 in) in any one direction and are less than $0.46 \mathrm{~m}$ (18 in) from the walkway surface. The Consumer Product Safety Commission (CPSC) has revoked the part of its standard that affected "glazed panels" or glazings next to doors and between two walking surfaces [51]. However, the major model code groups have indicated that they will provide this coverage. Glazed doors rank among the top ten hazardous consumer products. Sliding glass doors are specifically covered in the model codes and are primarily based upon the voluntary standard for safety glazing, ANSI 297.1 [52]. Sliding glass doors are sometimes used in passive designs for uniformity and potential ventilation in places not intended for use as entrances or doorways. The strict enforcement of the codes may require that such applications use safety glazing.

\subsubsection{Summary}

The structural design of buildings with passive solar techniques appears to be well-covered by the six regulatory documents included in this study. In cases where an analytical approach may not provide a reliable assessment, building codes allow prototypical testing to evaluate performance. There will be the need for more rigorous structural analysis and design and less reliance on handbook solutions since many of these techniques differ from currert conventional practices. As passive solar design becomes more widespread, these innovative practices will become part of the general practice. 


\section{SUMMARY AND RECOMMENDATIONS}

While much of the technology required for application of passive solar techniques in buildings is the same as conventional construction, there are many issues of a health and safety nature which are quite different and require further study and research. The drive to experiment and optimize thermal performance in buildings may introduce new and unusual health and safety considerations, as well as some questionable building practices. Building codes which regulate how buildings are constructed do not adequately address all these issues, even though there have been recent attempts to develop codes for the unique conditions associated with passive solar design.

The summary and conclusions of this study are as follows:

a. There is increasing evidence that correctly designed passive solar buildings have comfort characteristics which equal or exceed conventional buildings. Overall comfort is enhanced by the thermal stability of a well insulated building with large thermal mass used for storage of solar heat.

b. There is growing concern for the potential effects on health associated with a deteriorated indoor air quality in passive solar heating and cooling. This concern primarily results from the decrease in air infiltration and air movement in passive buildings. Other concerns are elevated temperatures at the point of collection/absorption of solar energy; increased humidity and potential for condensation, mold, etc.; and passage of air streams through structures. A reduction in fossil fuel combustion will help reduce the amount of particulate matter and thereby result in an improvement of the quality of indoor air.

c. Some materials and techniques common in passive solar buildings are believed to contribute to the concentration of contaminated air. The reduced level of air infiltration which passive solar technology shares with other energy conserving practices is known to contribute to this concentration. Prominent indoor air contaminants are formaldehyde, radon, and rock storage beds (dust, odors, mildew).

d. Structural design procedures are sufficiently well developed to provide for the incorporation of passive solar energy features in buildings.

e. The design of glazing for passive solar applications is well within the current state-of-the-art. There are unique concerns such as temperature fluctuations and the increased potential for injury from accidents that must be considered.

f. Passive construction techniques usually provide increased protection from physical forces such as storms and explosions. The increased use of masonry provides less combustible materials, reduced sources of toxic fumes, and perhaps increased stability against collapse. 
Masonry construction may also serve to help the control of fires through compartmentation and aid in fire confinement by preventing spread to adjacent building.

g. There is strong evidence that heavy use of heating appliances increases the incidence of fire. Data indicates that about 10 percent more fires per 1000 population occur in the northern states compared with those further south. Similar correlations for winter versus summer months and with the severity of winter weather give further indication that over-all fire incidence is related to the use of energy. The fact that passive solar buildings generally use significantly less fossil fuel energy is an additional factor in fire safety. Passive solar buildings also tend to have less ductwork than those with conventional forced air HVAC distribution systems, resulting in a reduced risk of fire spread through ductwork.

h. In general, the use of uninhabited basements, cellars, crawl spaces, cavity walls, areas above ceilings, or attic spaces as supply air make-up, exhaust air, or return air plenums is prohibited by present building regulations. Concealed vertical and horizontal spaces must be firestopped between storys and between bullding subdivisions. Unprotected passageways for air between these spaces would be precluded and air ducts with fire doors or dampers are generally required for penetration of a fire resistance rated assembly.

i. There are serious economic implications in applying existing building code provisions when solar retrofitting an existing building. Costs of modifications could trigger the "25-50 percent rule" and require compliance with the code for new construction. CABO [11] has incorporated a requirement which alleviates this problem.

Recommendations for further research and changes in building regulations needed to accelerate the acceptance of passive solar energy systems are as follows:

a. Investigation of selected buflding materials prevalent in passive solar construction is needed to determine the level of air pollutants emitted under varying conditions of air movement, temperature, and humidity. Low cost techniques should be developed to measure and monitor the pollutant level of selected pollutant categories in tightly sealed bulldings.

b. Additional research is needed regarding the long term effects of elevated temperature on the structural capacity of wood. Research is also necessary on how wood treatment practices (such as fire retardation) affect the the structural capacity of wood when this treated wood is exposed to elevated temperatures.

c. Building codes should be analyzed and alternative guidelines developed to reduce the impact of the codes restricting the area of skylights and roof panels to 25 to 30 percent of the area covered. 
d. The primary concern in the area of fire detection for passive solar systems involves the location of smoke detectors in residential occupancies. Guidelines should be developed for the placement of smoke detectors in residences with passive solar systems. Guidelines should address: (1) unusual paths of smoke travel, (2) combination with fire dampers and sprinklers, and (3) existence of special environmental conditions such as high temperatures.

e. Analysis of building code requirements for barriers to fire spread indicates that the code provisions generally were not written with passive solar systems in mind. For instance, are the air passageways in the attic and crawl space in an envelope dwelling considered uninhabited spaces or plenums and can the air space along a Trombe wall be considered an atrium? Modifications to building regulations are needed to clarify which requirements would be appropriate for passive solar systems, or at least, the objectives of fire spread requirements should be clearly stated in order that the designer may have the opportunity to fulfill them through alternative solutions.

f. The primary test method used on evaluating light transmitting plastics is ASTM D635. There are no studies now which correlate the results of the small scale tests with actual building fire performance. Since light transmitting plastics are incorporated in many passive solar designs, a study of this type is needed.

g. Research is needed on the effect of high temperatures on the performance of materials used for passive solar systems.

h. Material flammability concerns of most importance to passive solar energy systems are those related to interior finish materials and duct linings and covers. The primary concern in passive systems with the use of interior finishes are those used in insulation. Code requirements for movable insulation including special drapes and interior shutters are not clear. Code requirements for movable insulation need to be clarified. Since plastic materials are desirable for much of this insulation, it may be necessary to study the actual fire performance of typical insulation configurations.

i. Second means of egress may be a potential problem since many energy efficient and passive solar building designs seek to eliminate windows in north-facing bedrooms. Technical justification should be developed for regulator acceptance of alternate solutions which provide equivalent performance.

j. Beyond the obvious needs for a better understanding of the toxic products of combustion and their effects on humans, smoke movement in passive solar buildup should be studied further. Computer models are being developed to study smoke movement in buildup with conventional HVAC systems and those models may provide useful information when applied to passive solar designs. Guidelines should be developed for the installation of smoke control systems in buildings with passive features. 


\section{REFERENCES}

1. Balcomb, J. D., et al., Passive Solar Design Handbook, DoE/CS-0127/2, Los Alamos Scientific Laboratory (for DoE), January 1980.

2. Homann, P. and Hilleary, C., Solar Heating Materials Handbook, Environmental and Safery Considerations for Selection, Ana Chem., Inc., Albuquerque, N.M., 1981 (NTIS DoE/TIC-11374).

3. A Survey of Passive Solar Buildings, American Institute of Architects/ Research Corporation (for HUD), HUD-PDR-28702, 1979.

4. The First Passive Solar Home Awards, The Franklin Research Center (for HUD), HUD-PDR-376, 1979.

5. Basic Building Code, Building Officials and Code Administrators International, Inc., Homewood, IL, 1978 Edition.

6. National Building Code, National Conference of States on Bullding Codes and Standards, Inc., McLean, VA, 1976 Edition.

7. Standard Building Code, Southern Building Code Congress International, Inc., Birmingham, AL, 1980 Edition.

8. Uniform Building Code, International Conference of Building Officials, Whittier, CA, 1979 Edition.

9. Cooke, P. W. and Eisenhard, R. M., A Preliminary Examination of Building Regulations Adopted by the States and Major Cities, National Bureau of Standards NBSIR 77-1390, Washington, DC, 1977.

10. Metz, F. E., Berger, H. W. and Boone, T. A., Housing Conservation Technology, Department of Housing and Urban Development, Washington, DC, NTIS PB80-135692, 1977.

11. Recommended Requirements to Code Officials for Solar Heating, Cooling and Hot Water Systems, Council of American Building Officials (for DoE), DoE/CS/34281-01, June 1980 .

12. Gross, J. G., Pielert, J.H., and Cooke, P. W., Impact of Building Regulations on Rehabilitation - Status and Technical Needs, NBS Technical Note 998, May 1979.

13. Rehabilitation Guidelines, Volume 1, Guidelines for Setting and Adopting Standards for Building Rehabilitation, Department of Housing and Urban Development, HUD-PDR-613-1, Washington, DC.

14. Environment, Health and Safety, and Social Impact, DoE Solar Energy Program Summary Document - FY81, January 1980. 
15. Bregsse, P., The Health Cost of 'Tight' Houses, Journal of the American Medical Association, Vol. 245, No. 3, January 16, 1981.

16. Indoor Air Pollution Scrutinized in Congressional Clean Air Act Study, ASHRAE Journal, April 1981.

17. Long, K., Pierson, S. and Brennan, C., Problems Associated with the Use of Urea-Fomaldehyde Foam (A Residential Insulation, Part I: The Effects of Temperature and Humidity on Formaldehyde Released from Urea-Formaldehyde Foam Insulation (for DoE), ORNL/SUB-7559/1, University of Iowa, September 1979.

18. Godish, T., Recognition of Building-Related Illness, Natural Resource Notes, Ball State University, 1981.

19. Harris, J. et al., Toxicology of Urea-Formaldehyde and Polyurethane Foam Insulation, Journal of the American Medical Association, Vo1. 245, No. 3, January 1981 .

20. Hadley, J., Energy Conservation and Indoor Air Quality, ASHRAE Journal, March 1981.

21. Swedjemark, G., Radon in Dwellings in Sweden, Symposium on Natural Radiation Environment III, Houston, Texas, 1978.

22. Scott, L. and Scol1, M., Indoor Air Pollution in Passive Structures, Proceedings, 5th National Passive Conference, Amherst, MA, October 1980 .

23. Kusuda, T., Hunt, C. and McNal1, P., Radioactivity (Radon and Daughter Products) As a Potential Factor in Building Ventilation, ASHRAE Journal, Vol. 12, No. 7, 1979 .

24. The Radiation in Sun Homes, The Swedish National Institute for Radiation Safety, Information Pamphlet, 1976.

25. Silberstein, S., Radon in Six Test Buildings at the National Bureau of Standards, National Bureau of Standards Letter Report, Part 1

(September 1981) and Part 2 (December 1981).

26. Minimum Property Standards for Single-Family Housing, U.S. Department of Housing and Urban Development, HUD Circular 4900.1, Washington, DC, 1980.

27. Life Safety Code, NFPA No. 101, National Fire Protection Association, Battery March Park, Quincy, MA, 1981.

28. Standard for Ventilation for Acceptable Air Quality, American Society of Heating, Refrigerating and Air Conditioning Engineers, ASHRAE Standard 62-81, New York, NY, 1981. 
29. Residential Solar Demonstration Programs: Findings of the Passive Solar Residential Design Competition and Demonstration, Real Estate Corporation, U.S. Department of Housing and Urban Development, 1980 .

30 Thermal Environmental Conditions for Human Occupancy, Standard 55-81, ASHRAE, 1981.

31. Metz, F. E. et al., Performance Criteria for Solar Heating and Cooling Systems, Draft NBSIR 80-2095, National Bureau of Standards for the Department of Housing and Urban Development, April 1982.

32. Health and the Environment, ASHRAE Fundamental Handbook, ASHRAE, 1977.

33. ASHRAE Handbook of Fundamentals (1981), ASHRAE, Atlanta, Georgia.

34. Energy Conservation in New Building Design, ASHRAE Standard 90-75, Atlanta, GA.

35. Loxsom, F. ed., Passive and Hybrid Cooling Workshop Handbook, Philadelphia, PA, May 1981.

36. How to Avoid Condensation Problems, Housing, April 1981.

37. Burberg, P., Condensation, How to Avoid It, Architectural Journal, October 1979.

38. Yerges, L., Sound, Noise, and Vibration Control, Van Nostrand Reinhold, New York, 1969.

39. Harvey, C. S., Fire Occurs Within Solar Panel, Fire Command, Vol. 47, No. 9, pp. 40-41, September 1980 .

40. Walton, W. D., Solar Collector Fire Incident Investigation, National Bureau of Standards, NBSIR 80-2326, Washington, DC, August 1981.

41. Moore, D. C., Lessons Learned from the HUD Solar Demonstration Program, Solar Engineering, pp. 16-18, 45, March 1981.

42. Ignition of Wood and Wood Products, Fire Protection Handbook, Fifteenth Edition, Pp. 4-11 and 4-12, Quincy, MA, September 1981.

43. Basic Mechanical Code, Building officials and Code Administrator International Inc., Homewood, Illinois, 1978.

44. Standard Mechanical Code, Southern Building Code Congress International, Inc., Birmingham, Alabama., 1980.

45. Uniform Mechanical Code, International Conference of Building Officials, Whittier, California, 1979. 
46. Earth Sheltered Housing Design, Guidelines, Examples and References, The Underground Space Center, University of Minnesota, Minnesota Energy Agency, Van Nostrand, Reinhold, NY, 1980.

47. Earth Sheltered Housing: Code, Zoning, and Financing Issues, University of Minnesota, NTIS No. PB81-118150, April 1980.

48. Wood Handbook: Wood as an Engineering Material, Forest Products Laboratory, Agricultural Handbook No. 72, August 1972.

49. McGuire, J. H., Limiting Safe Surface Temperature of Combustible Materials, Fire Technology, August 1969.

50. Home Safety Guidelines for Architects and Builders, The Buffalo Organization for Social and Technological Innovation, NBS-GCR 78-156, December 1978 .

51. Building Sclences, Vol 2, No. 10, The National Institute of Building Sciences.

52. Performance Specifications and Methods of Tests for Safety Glazing Material Used in Buildings, ANSI Standard 297.1a - 1977, New York, NY. 
BIBLIOGRAPHIC DATA

NBSIR 82-2554

HEALTH AND SAFETY CONSIDERATIONS FOR PASSIVE SOLAR HEATED AND COOLED BUILDINGS

5. $A \cup T H O R(S)$

F. E. Metz, J. H. Pielert, P. W. Cooke, D. Walton

6. PERFORMING ORGANIZATION (If joint or other than NBS, see instructions)

NATIONAL BUREAU OF STANDARDS

DEPARTMENT OF COMMERCE

WASHINGTON, D.C. 20234

9. SPONSORING ORGANIZATION NAME AND COMPLETE ADDRESS (Street, City, State, ZIP)

7. Contract/Grant No.

DE-AI01-76PR06010

8. Type of Report \& Period Covered Final

U.S. Department of Energy

Office of Solar Heat Technologies

Passive and Hybrid Solar Energy Division

Washington, D.C. 20585

10. SUPPLEMENTARY NOTES

[Document describes a computer program; SF-185, FIPS Software Summary, is attached.

11. ABSTRACT (A 200-word or less factual summary of most significant information. If document includes a significant bibliography or literature survey, mention it here)

Passive solar buildings often introduce alternative construction techniques, and new materials and applications which presently have limited guidelines concerning safe application. This report discusses research conducted to pursue the nature of health and safety considerations in application of solar passive technology to buildings and how they would be affected by current building regulatory requirements. Health and safety considerations associated with solar passive systems are discussed including: indoor air quality; structural safety; fire safety; and environmental issues such as ventilation, illumination, temperature control, humidity and noise control. The report also identifies technical issues and research needs for addressing health and safety issues in passive solar technology.

12. KEY WORDS (Six to twelve entries; alphabetical order: capitalize only proper names; and separate key words by semicolons) Buildings; building regulations; energy; enforcement; health and safety; passive design; solar energy; standards.

\section{AVAILABILITY}

[X] Unlimited

For Official Distribution. Do Not Release to NTIS

Order From Superintendent of Documents, U.S. Government Printing Office, Washington, D.C. 20402.

X] Order From National Technical Information Service (NTIS), Springfield, VA. 22161
14. NO. OF PRINTED PAGES

$$
65
$$

15. Price 

